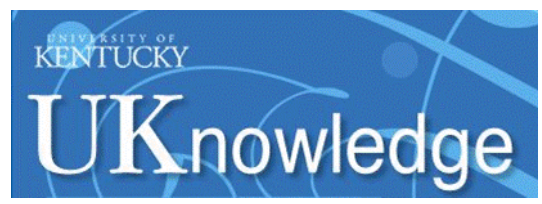

University of Kentucky

UKnowledge

1996

\title{
Russian Noun Stress and Network Morphology
}

Dunstan Brown

University of Surrey, d.brown@surrey.ac.uk

Greville Corbett

University of Surrey, g.corbett@surrey.ac.uk

Norman Fraser

Andrew R. Hippisley

University of Kentucky, andrew.hippisley@uky.edu

Alan Timberlake

Columbia University, at2205@columbia.edu

Follow this and additional works at: https://uknowledge.uky.edu/lin_facpub

Part of the Linguistics Commons

Right click to open a feedback form in a new tab to let us know how this document benefits you.

\section{Repository Citation}

Brown, Dunstan; Corbett, Greville; Fraser, Norman; Hippisley, Andrew R.; and Timberlake, Alan, "Russian Noun Stress and Network Morphology" (1996). Linguistics Faculty Publications. 45.

https://uknowledge.uky.edu/lin_facpub/45

This Article is brought to you for free and open access by the Linguistics at UKnowledge. It has been accepted for inclusion in Linguistics Faculty Publications by an authorized administrator of UKnowledge. For more information, please contact UKnowledge@lsv.uky.edu. 


\section{Russian Noun Stress and Network Morphology}

Digital Object Identifier (DOI)

https://doi.org/10.1515/ling.1996.34.1.53

This article is available at UKnowledge: https://uknowledge.uky.edu/lin_facpub/45 


\title{
Russian noun stress and network morphology*
}

\author{
DUNSTAN BROWN, GREVILLE CORBETT, NORMAN FRASER, \\ ANDREW HIPPISLEY, and ALAN TIMBERLAKE
}

\section{Abstract}

We present a network morphology analysis of Russian noun stress. Nouns have a default fixed stem stress, but some nouns have nondefault stress that may deviate in a way that is determined by the form's position within the paradigm; different declensions prefer particular patterns as their nondefault choices. Membership of a particular declension, it is argued, constrains the range of possible stress patterns. Stress is represented as a hierarchy with limited deviation in terms of number and, less often, case. Indices in the declension hierarchy are addressed to nodes in the stress hierarchy. These indices correspond to rank orderings that declensions have for stress patterns. Lexical items inherit a default value for index rank but may override this. It is not possible for any override value to be given at the lexical entry, as this has to be evaluated in the declension hierarchy. The use of cyclicity in metrical approaches is considered, and it is concluded that lexical marking is still required. In addition, it is predicted that accusative forms that are syncretic with the nominative or genitive on the basis of animacy must have the same stress as the form with which they are syncretic.

\section{Introduction}

In this paper we outline an approach to stress assignment in Russian that captures the relationship between declensional class and stress patterns, ignored in most current approaches to stress. This approach is expressed in terms of the framework of network morphology (Corbett and Fraser 1993) and represented in the lexical knowledge representation language DATR, developed by Evans and Gazdar (1989a, 1989b). Corbett and Fraser (1993) have already demonstrated how a network morphology treatment of Russian inflectional morphology, by virtue of its use of default inheritance, can deal with apparent morphosyntactic 
mismatches related to animacy marking and capture significant generalizations about syncretism. In addition, it has also been shown how an analysis in DATR might deal with the problematic case of conflict in Russian genitive plural assignment (Brown and Hippisley 1994).

In section 2 we present the data for Russian nouns and show that there is more than a merely superficial relationship between declensions and stress patterns. In the next section (section 3) we introduce the network morphology framework and its key components. In section 4 we consider the Russian data in terms of network morphology. Finally, we consider an account based on cyclicity and argue that this still requires extensive lexical marking in any event (sections 5 and 6).

\section{The Russian data}

Halle (1975) drew a contrast between the principle-based explanation of the Russian accentual system and the taxonomic description of accentual patterns. These taxonomies were contrasted with "scientific descriptions." The stress patterns outlined by Redkin (1971) and others were considered no more than taxonomic descriptions. This view of accentual patterns has continued up to the present in generative works. However, although the Russian data were handled in such analyses by the use of minor rules for stress retraction (e.g. Halle 1975), one important aspect - namely the relationship between stress pattern and paradigm - was largely overlooked. This trend is continued in modern frameworks.

\subsection{Russian declensional classes}

We assume the four declensional classes for Russian as argued for in Corbett (1982) and Corbett and Fraser (1993). ${ }^{1}$ The Russian declensions are given in Table 1 in phonological transcription. ${ }^{2}$ For each lexeme in this table the forms have stress on the stem throughout the paradigm, and this corresponds to the first stress pattern, stress pattern A, where nouns follow the two generalizations for stress assignment indicated below.

\subsection{Russian noun stress patterns}

Two generalizations can be made about stress in Russian nouns: stress is somewhere on the stem, and it is immobile. When these generalizations
Table 1. Russian declensional classes

\begin{tabular}{|c|c|c|c|c|}
\hline & $\begin{array}{l}\text { I } \\
\text { zakáz } \\
\text { 'order' }\end{array}$ & $\begin{array}{l}\text { II } \\
\text { kómnata } \\
\text { 'room' }\end{array}$ & $\begin{array}{l}\text { III } \\
\text { tetrád' } \\
\text { 'exercise book' }\end{array}$ & $\begin{array}{l}\text { IV } \\
\text { bl'údo } \\
\text { 'dish' }\end{array}$ \\
\hline \multicolumn{5}{|l|}{ SG } \\
\hline nom & zakáz & kómnata & tetrád' & bl'údo \\
\hline acc & zakáz & kómnatu & tetrád' & bl'údo \\
\hline gen & zakáza & kómnati & tetrád'i & bl'úda \\
\hline dat & zakázu & kómnate & tetrád'i & bl'údu \\
\hline inst & zakázom & kómnatoj & tetrád'ju & bl'údom \\
\hline loc & zakáze & kómnate & tetrád'i & bl'úde \\
\hline \multicolumn{5}{|l|}{$\mathrm{PL}$} \\
\hline nom & zakázi & kómnati & tetrád'i & bl'úda \\
\hline acc & zakázi & kómnati & tetrád'i & bl'úda \\
\hline gen & zakázov & kómnat & tetrád'ej & bl'úd \\
\hline dat & zakázam & kómnatam & tetrád'am & bl'údam \\
\hline inst & zakázam'i & kómnatam'i & tetrád'am'i & bl'údam'i \\
\hline loc & zakázax & kómnatax & tetrád'ax & bl'údax \\
\hline
\end{tabular}

are not adhered to, a certain set of patterns can be found. Following others (Redkin 1971; Fedjanina 1976; Zaliznjak 1977; Corbett 1989), we can define four basic patterns according to whether stress is on the stem or ending in each of the two numbers. ${ }^{3}$

Deviations from these four basic patterns can occur only in the nominative (or accusative) plural and accusative singular, when stress would otherwise be on the ending in that number. Furthermore, if deviation is theoretically possible in both positions, then it is found in the accusative singular only if it is also found in the nominative/accusative plural. This therefore means that there are four subpatterns: two for pattern B (ending stress in singular and plural), one for pattern $\mathrm{C}$ (ending stress in plural), one for pattern $\mathrm{D}$ (ending stress in singular, predesinential stress in plural), as in Halle (1970: 172-173). Note that pattern A is the result of the two main generalizations mentioned above (stress is on the stem and is immobile).

The examples of the declensional classes in Table 1 all have stress pattern A, where there is no ending stress. Examples (1)-(7) show nouns that belong to one of the four declensional classes in Table 1 but have different stress patterns. In the first three sets of examples only the nominative singular, dative singular, and dative plural are given to illustrate the possible change between singular and plural. In examples (4) -(7) the accusative singular and/or the nominative plural are given, 
as these are the only cases that may differ, and only when stress is on the ending in all the other cases of a number. ${ }^{4}$

(1) Pattern B - stress on the ending in both singular and plural: nom(inative) sing(ular) dat(ive) sing(ular)

$\begin{array}{ll}\text { stol } & \text { stolú } \\ \text { č'ertá } & \text { č'erté } \\ \text { voš } & \text { vší } \\ \text { vešč' estvó } & \text { vešč' estvú } \\ \text { dat(ive)pl(ural) } & \text { gloss } \\ \text { stolám } & \text { 'table' } \\ \text { č'ertám } & \text { 'characteristic' } \\ \text { všám } & \text { 'louse' } \\ \text { vešč' estvám } & \text { 'substance' }\end{array}$

(2) Pattern $\mathrm{C}$ - stress on the initial syllable in the singular and on the ending in the plural:

$\begin{array}{llll}\text { nom sing } & \text { dat sing } & \text { dat pl } & \text { gloss } \\ \text { mozg } & \text { mózgu } & \text { mozgám } & \text { 'brain' } \\ \text { télo } & \text { télu } & \text { telám } & \text { 'body' }\end{array}$

(3) Pattern D - stress on the ending in the singular and in the initial/predesinential position in the plural: $^{5}$

$\begin{array}{llll}\text { nom sing } & \text { dat sing } & \text { dat pl } & \text { gloss } \\ \text { rožók } & \text { rožkú } & \text { róžkam } & \text { 'little (animal) horn' } \\ \text { dirá } & \text { diré } & \text { díram } & \text { 'hole' } \\ \text { s'oló } & \text { s'olú } & \text { s'ólam } & \text { 'village' }\end{array}$

(4) Pattern $\mathrm{Bi}$ - the stress pattern is as for pattern B, but the nominative plural has initial stress:

$\begin{array}{lllll}\text { nom sing } & \text { dat sing } & \text { nom pl } & \text { dat pl } & \text { gloss } \\ \text { kon' } & \text { kon'ú } & \text { kón'i } & \text { kon'ám } & \text { 'horse' } \\ \text { skovoradá } & \text { skovorodé } & \text { skóvorodi } & \text { skovorodám } & \text { 'frying pan' } \\ \text { kril'có } & \text { kril'cú } & \text { kríl'ca } & \text { kril'cám } & \text { 'porch' }\end{array}$

(5) Pattern $\mathrm{Bii}$ - the stress pattern is as for pattern $\mathrm{Bi}$, but the accusative singular has initial stress:

nom sing acc sing dat sing nom pl dat pl gloss borodá bórodu borodé bórodi borodám 'beard'
(6) Pattern $\mathrm{Ci}$ - the stress pattern is as for pattern $\mathrm{C}$, but the nominative plural has initial stress:

$\begin{array}{lllll}\text { nom sing } & \text { dat sing } & \text { nom pl } & \text { dat pl } & \text { gloss } \\ \text { zub } & \text { zúbu } & \text { zúbi } & \text { zubóv } & \text { 'tooth' } \\ \text { dól'a } & \text { dól'e } & \text { dól'i } & \text { dol'ám } & \text { 'portion' } \\ \text { plóšč'ad' } & \text { plóščcad'i } & \text { plóšč'ad'i } & \text { plošč'ad'ám } & \text { '(city) square' } \\ \text { úxo } & \text { úxu } & \text { úši } & \text { ušám } & \text { 'ear' }\end{array}$

(7) Pattern $\mathrm{Di}$ - stress pattern is as for pattern $\mathrm{D}$, but the accusative singular has initial stress:

nom sing acc sing dat sing nom pl dat pl gloss

The patterns are distributed across declensional classes in such a way as to suggest that there is a priority relationship between declensional class and stress pattern. Table 2 is based on information derived from Zaliznjak (1977) and gives the overall number of nouns in the lexicon that exhibit one of the eight stress patterns discussed above (given in the leftmost column together with a description in the column to its right). The righthand column indicates the total number of noun lexemes per stress pattern. The bottom row indicates the numbers of nouns in each declensional class, and the total number of nouns is given in the rightmost

Table 2. Stress and Russian noun declensions ${ }^{6}$

\begin{tabular}{|c|c|c|c|c|c|c|}
\hline Pattern & Description $\mathrm{sg} / \mathrm{pl}$ & Decl I & Decl II & Decl III & Decl IV & Total (pattern) \\
\hline A & stem/stem & 18122 & 12884 & 3811 & 5486 & 40303 \\
\hline B & ending/ending & 2104 & 420 & 5 & 148 & 2677 \\
\hline (Bi) & $\begin{array}{l}\mathrm{B}, \text { nom pl has } \\
\text { initial stress }\end{array}$ & 5 & 39 & 0 & 4 & 48 \\
\hline (Bii) & $\begin{array}{r}\mathrm{Bi}, \text { acc sg has } \\
\text { initial stress }\end{array}$ & 0 & 21 & 0 & 0 & 21 \\
\hline $\mathrm{C}$ & stem/ending & 394 & 0 & 0 & 43 & 437 \\
\hline (Ci) & $\begin{array}{r}\mathrm{C}, \text { nom pl has } \\
\text { initial stress }\end{array}$ & 50 & 3 & 113 & 2 & 168 \\
\hline D & ending/stem & 15 & 229 & 0 & 83 & 327 \\
\hline (Di) & $\begin{array}{l}\mathrm{D} \text {, acc sg has } \\
\text { initial stress }\end{array}$ & 0 & 15 & 0 & 0 & 15 \\
\hline \multicolumn{2}{|c|}{ Total (per declension) } & 20690 & 13611 & 3929 & 5766 & 43996 \\
\hline
\end{tabular}


column of that row. It is very clear, for instance, that declension I accounts for the largest group of nouns.

\subsection{Paradigms and priorities}

We can derive a number of generalizations from the information in Table 2. The first generalization is that the overwhelming majority of nouns in Russian follow pattern A, irrespective of declension class. In addition, we also see that pattern $\mathrm{B}$ is the next choice for nouns as a whole, since it is the next choice for three of the four declensions. After this, the situation becomes more complicated. Table 3 summarizes the possible choices for a given declension class and ranks them.

Class III nouns do not follow the general pattern for nouns, in that they have pattern $\mathrm{Ci}$ as a second priority. The majority of nouns follow a pattern that obeys one of the generalizations mentioned in section 2.2. When they follow pattern B, they follow the second generalization, that stress will be immobile. Each declension then has a number of priorities for a given stress pattern, with declension II showing the greatest number of possible stress patterns.

As can be seen from Table 2 the quantitative difference in representation of stress pattern in a particular declension is clearcut between the first, second, and third choices for any of the four declensions. After the fourth ranked choice the difference in representation is less clearcut. As we shall see in section 4.2 , this motivates our choice of indices.

As will be discussed below, the major issue for a network morphology account of these data is the question of the number of desinences that a language allows for, and establishing relations between lexemes that have phonologically identical endings with different stress. We also go on to

Table 3. Priorities for each declension

\begin{tabular}{lllll}
\hline Stress pattern & $\begin{array}{l}\text { Declension: } \\
\text { I }\end{array}$ & II & III & IV \\
\hline A & 1 & 1 & 1 & 1 \\
$\mathrm{~B}$ & 2 & 2 & 3 & 2 \\
$\mathrm{C}$ & 3 & $\mathrm{n} / \mathrm{a}$ & $\mathrm{n} / \mathrm{a}$ & 4 \\
$\mathrm{D}$ & 5 & 3 & n/a & 3 \\
$\mathrm{Bi}$ & 6 & 4 & n/a & 5 \\
$\mathrm{Bii}$ & n/a & 5 & n/a & n/a \\
$\mathrm{Ci}$ & 4 & 7 & 2 & 6 \\
$\mathrm{Di}$ & $\mathrm{n} / \mathrm{a}$ & 6 & n/a & n/a \\
\hline
\end{tabular}

show that our approach makes predictions regarding the possible changes in the stress patterns allowed. This is determined by the membership of a declension. We explain this in detail in section 4; as an example of what we mean, we can illustrate by saying that it would just not be possible for a noun lexeme belonging to class III to innovate a stress pattern such as Bii. It might be considered that these patterns fall out through the use of cyclicity and specifying the case/number morphemes as having or not having stress. As will be shown, the issue then centers upon the question of how many desinences there are in a given paradigm, thus bringing the status of paradigms into sharp focus.

\section{Network morphology}

To investigate further the relationship between stress and declensional class in Russian, we adopt the framework of network morphology (Corbett and Fraser 1993; Brown and Hippisley 1994; Fraser and Corbett 1995). Network morphology is particularly well suited to this purpose for two reasons. First, it offers a more sophisticated account of the paradigm than is usual. Second, it is particularly simple in this framework to construct accounts that combine different levels of linguistic information, including prosody, phonology, and morphology.

Network morphology builds on a view of language as a network of linguistic information. A network consists of a collection of nodes and connections between nodes. Parcels of information are stored at the nodes, and the internode connections can be viewed as relationships between nodes. The connectivity of the network determines which information is available at which node. This view of language is not new; versions of it may be found, for example, in word grammar (Hudson 1990; Fraser and Hudson 1992), and in a number of recent natural language processing computer systems (summarised in Daelemans et al. 1992). With its concentration on describing information structures rather than rules, network morphology is clearly a declarative framework.

There are strong similarities between the general approach to representing lexical knowledge adopted in network morphology and that found in semantic network systems for representing real world knowledge (for example, see Fahlman 1979). For this reason, some people find nonlinguistic examples helpful in grasping the basic principles of network morphology. Such examples may be found in Corbett and Fraser (1993: 119), Brown and Hippisley (1994: 52), amd Fraser and Corbett (1995: 123-125). Our introduction to network morphology here will be structured around formal definitions of its key components: networks, nodes, 
facts, attributes, values, default inheritance, and orthogonal multiple inheritance.

\section{Networks}

Lexical knowledge is organized as a network whose basic elements are nodes and facts, and whose structure consists of relationships between basic elements.

\section{Nodes}

A node is a named location at which one or more facts may be stored.

Recall the Russian nominal declensions shown in Table 1 above. It is customary to think of these as four distinct classes that exist alongside each other as discrete entities. A graphic representation of this view is shown in Figure 1.

However, the declensional classes can profitably be regarded as components of a single network structure related by virtue of their proximity to a shared "parent" node. Figure 2 illustrates this.

In this network, the nodes are shown in boldface, while the lines connecting nodes represent structural relations between them. There is, of course, little advantage simply in asserting that the declensional classes may be thought of as belonging to a single structure; the primary motivation for adopting a network analysis is that it readily allows valuable generalizations to be made that could only be made with considerable difficulty in treatments that regard the declensional classes as discrete monoliths. We shall revisit this issue below once some extra details of network morphology have been introduced.

As we have noted, nodes are named locations at which facts - that is, linguistic propositions - may be stored. As the following definitions provide, facts consist of relationships between paths and values.

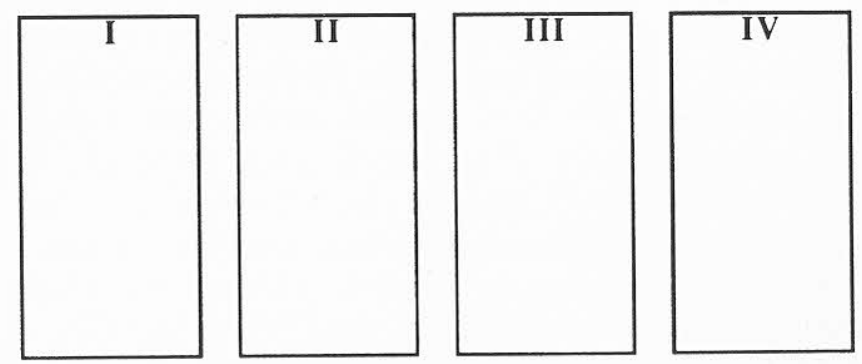

Figure 1. Declensional classes as discrete entities

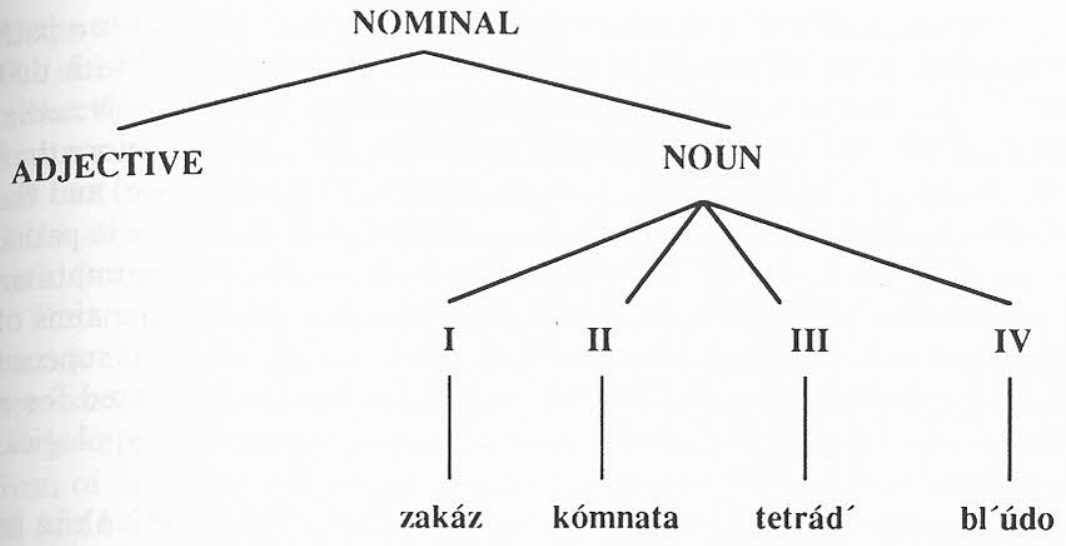

Figure 2. A simple Russian nominal network

Facts

A fact consists of a path: value pair. A value may be stated directly or referenced indirectly by way of another path. If, at the end of a chain of reference, no value can be found for a path, the fact in which that path appears is undefined.

Paths

Paths are ordered attribute structures. Paths may consist of zero or more attributes. Paths increase in specificity from left to right.

Attributes

Attributes are atomic symbols.

Values

Values may be atomic or consist of a sequence of atoms.

So far, we have presented some high-level structural decisions that network morphology embodies. However, it is axiomatic in the network morphology program that these choices should be encoded in an explicit, well-defined, and computable formalism. Some example network morphology facts are shown in just such a formalism in (8).

(8) Zakáz:
a. 〈stem $\rangle==$ zakáz
b. $\langle$ nom sg $\rangle==\langle$ stem $\rangle$
c. $\langle$ gen $s g\rangle==\langle$ stem $\rangle$ a.

A collection of facts is called a theory. Example (8) shows a fragment of the theory for the lexical entry zakáz. Here, zakáz is the node at which 
the three facts shown in (8a)-(8c) are stored. ${ }^{7}$ In $(8 a)\langle$ Stem $\rangle$ is a path containing one attribute, while zakáz is the value associated with that path. The intent of this fact is clear: the stem of this lexical item is zakáz. Whereas (8a) has one attribute in its path, $\langle$ stem $\rangle,(8 b)$ has more than one, $\langle$ nom sg $\rangle$. This path designates both the case (nominative) and the number (singular) of the noun. Order of attributes is significant in paths, as we shall see later. The formalism used here places no constraints on the attributes that may be used in a path. However, one of the aims of the network morphology enterprise is to construct the minimal superset of atoms (representing linguistically significant features) required for a theory of language sufficiently rich to extend across the typological spectrum.

Values may also be either atomic or sequences. The value zakáz in (8a) is atomic. However, the literal form $\langle$ stem $\rangle$ in (8b) is neither atomic nor sequential. The whole is not itself a value; it is a reference to a value. The value of the nominative singular of Zakáz can be found by looking at the stem of Zakáz. Example (8c) is very similar except that it shows how a reference to a value $(\langle\mathrm{stem}\rangle)$ can be combined with an atomic value (a) to produce a sequential value. This fact can be summarized as follows: the genitive singular form of Zakáz is the stem of Zakáz (i.e. zakáz) followed by $-a$.

A network morphology theory can be evaluated to produce a set of theorems. If the theory in (8) is evaluated, it will yield the theorems shown in (9). By convention, the relationship between paths and values prior to evaluation (i.e. in theories) is expressed using the $==$ operator, while that between paths and values following evaluation (i.e. in theorems) is expressed using the = operator.

(9) a. Zakáz:〈stem〉= zakáz.

b. Zakáz:〈nom sg $\rangle=$ zakáz.

c. Zakáz: 〈gen sg $\rangle=$ zakáz a.

Consider again the information encoded in (8). Of the three facts presented there, only (8a) is particular to this noun. All other nouns in declensional class I form their nominative and genitive singulars in just the same way. This regularity can be expressed very simply in network morphology, as shown in (10).

(10) N_I:

$$
\begin{aligned}
& \text { a. }\langle\text { nom sg }\rangle==\text { "〈stem }\rangle " \\
& \text { b. }\langle\text { gen } s g\rangle=="\langle\text { stem }\rangle " a \text {. } \\
& \text { Zakáz: } \\
& \text { c. }\langle\rangle==\text { N_I } \\
& \text { d. }\langle\text { stem }\rangle==\text { zakáz. }
\end{aligned}
$$

At the node N_I the path "〈stem >" is enclosed in double quotes ([10b]) The double quotes are indirection markers ([10a] and [10b]). They refer indirectly to a value that may differ for nodes connected to N_I. Here, for example the value of 〈stem〉 for Zakáz is zakáz, but this obviously will not be the case for any other noun of declensional class I. The declaration "〈stem $\rangle$ " is a generalization over all possible values for the path 〈stem〉 for nouns that belong to N_I.

The most important fact to understand here is (10c). This appears to encode an empty path \langle\rangle . To appreciate what is going on here, it is necessary to understand a little more about the way in which paths work. We have already seen the path $\langle$ nom $\mathbf{s g}\rangle$. This picks out that nominative form of the noun that is also singular. However, it is possible to refer to all (i.e. both) nominatives by using the underspecified path $\langle$ nom $\rangle$. Paths increase in specificity from left to right. Now the import of the \langle\rangle path in (10c) ought to be at least a little clearer: this is the maximally underspecified path. Every attribute structure allowed by the theory is described by (10c), with the exception of the $\langle$ stem $\rangle$ attribute. This is excluded, because more specific (i.e. longer) paths always take precedence over less specific (shorter) ones, so that a one-attribute path, for example, is more specific than an empty path. The theory fragment shown in (10) can be summarized as follows: the stem of Zakáz is zakáz; to find out anything else about this word inherit the facts stored at the N I node. The net effect of (10) is in effect the same as (8), from which the theorems given in (9) can be derived. The difference is that (10a) and (10b) need only be stated once to be available to every first declension noun in the language.

What we have seen here is an instance of default inheritance. In the presence of an explicit licensing fact such as (10c), one node can inherit facts from another. Arbitrarily long inheritance chains may thus be set up. For example, most nouns in Russian form their locative singular in $-e$. This fact can be encoded at the NOUN node, and the Zakáz node can be made to inherit it via the N I node. (Since first declension nouns are clearly nouns, N_I should inherit from NOUN.) This is called default inheritance because inheritance is only called upon to supply general information in the absence of more specific information. If such specific information exists - as in the case of lexical exceptions - the default information is never accessed. A slightly more formal description of default inheritance is given below:

Default inheritance

If $\mathrm{X}$ and $\mathrm{Y}$ are nodes, $\mathrm{X}$ may inherit from $\mathrm{Y}$ if a fact of the form \langle\rangle$==\mathrm{Y}$ is included at $\mathrm{X}$. All facts at $\mathrm{Y}$ become available at $\mathrm{X}$, except those having a path that is already present in a fact at $\mathrm{X}$. 
A node may inherit from more than one source. Consider third declension Russian nouns, for example. A slightly modified fragment from the network morphology theory presented in Corbett and Fraser (1993: 137) is shown below:

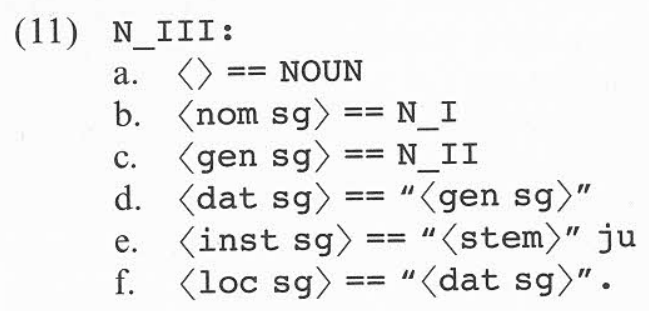

Some facts that are particular to declensional class III nouns are provided in (11d)-(11f). Notice the way in which syncretisms are encoded in (11d) and (11f). Just as identities within a single paradigm can be established, so identities between declensional classes can also be stated. (11b) states that declension III nouns follow declension I nouns in nominative singular formation, whereas (11c) requires them to follow declension II nouns in genitive singular formation. The linguistic intuition that there is a distinction between identities within a declension and between declensions finds a formal reflex in the distinct notations required to achieve this here. The normal source from which N_III inherits is the Noun node, as indicated by use of the maximally underspecified 〈> path.

When a node can inherit from more than one source (so-called multiple inheritance), there is a potential for confusion, since an attempt could be made to inherit values for the same path from different sources. To avoid this, a constrained version of multiple inheritance called orthogonal multiple inheritance (Touretzky 1986: 73) is used in network morphology:

Orthogonal multiple inheritance

If, at a given node, some number of facts may potentially be inherited whose paths differ only in specificity, then only the fact containing the more specific path may be inherited.

We began this introduction to network morphology by reflecting on the possibility of a network account of the noun declensions of Russian. Such an account has been developed in considerable detail in Corbett and Fraser (1993), Brown and Hippisley (1994), and Fraser and Corbett (1995). The main lines of inheritance in this account are shown in Figure 3. This differs from the initial version of Figure 2 in respect of the existence of node N_O. There has been a long debate concerning the optimum number of declensional classes in Russian. Though various

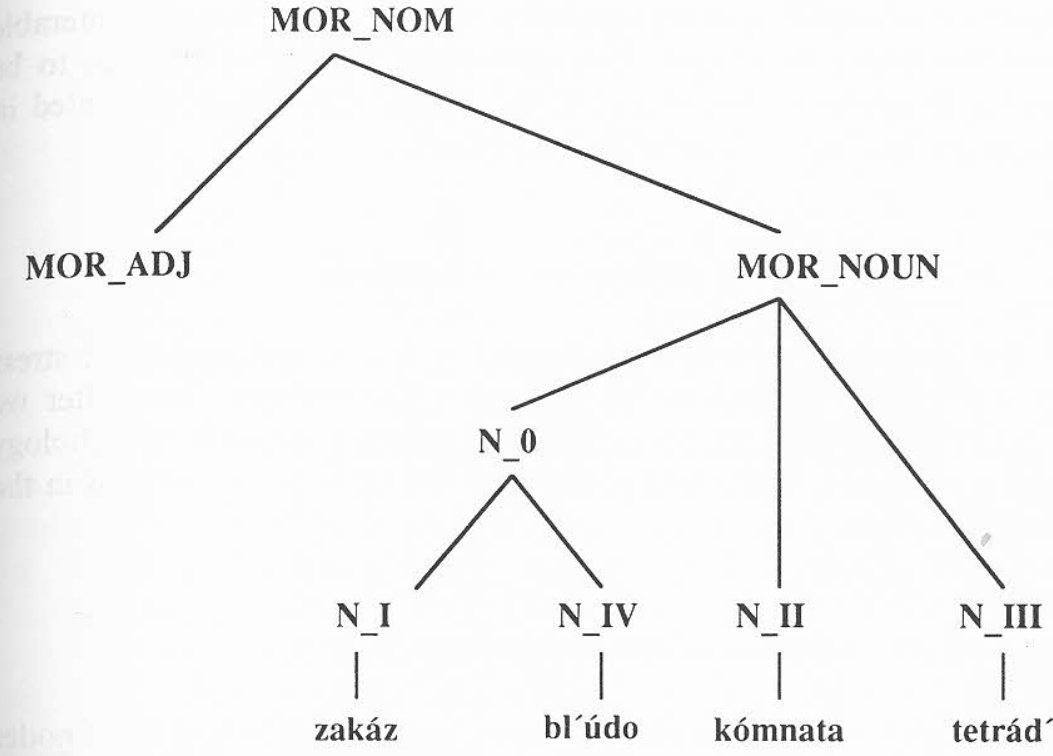

Figure 3. A more sophisticated Russian nominal network

suggestions have been made, the main difficulty is choosing between analyses based on three classes and those based on four. In a network morphology framework, the issues are seen to be valid, but the requirement to polarize is not. There are strong arguments for the creation of distinct classes I and IV; at the same time, if these were set up as completely independent classes there would be an unacceptable amount of redundancy between them. The solution is to set up a supernode N_O, at which all of the facts common to N_I and N_IV can be stored with maximum economy.

Linguistic arguments for this arrangement will not be rehearsed here. They principally revolve around the very considerable descriptive economies that are possible, though they are not confined to these. The key thing to note is that in subsequent discussions of paradigmatic stress in this paper, a sophisticated network-based understanding of declensional class will be presupposed.

Network morphology is a linguistically motivated framework. The notation in which the ideas of network morphology are expressed formally was developed by Roger Evans and Gerald Gazdar and is known by the name DATR (Evans and Gazdar 1989a, 1989b; Gazdar i.p.). ${ }^{8}$ This formalism is a powerful tool for lexical research. Not least among its benefits is the existence of computer interpreters that can take a theory 
expressed in DATR as input and deliver the full set of theorems inferable from the theory as output. This allows the validity of theories to be checked properly by inspection of the results. The theory presented in this paper has been validated in this fashion.

\section{The assignment of stress in network morphology}

In this section we consider the representation of morphological stress and how this is related to the main nominal network. Thereafter we demonstrate how an analysis embedded within a network morphology framework makes interesting predictions related to stress patterns in the nominal system.

\subsection{The representation of morphological stress}

We represent the Russian nominal stress system as a hierarchy of nodes and facts (Figure 4). The corresponding value for any path in the stress hierarchy can either be "defined" or "undefined." 9 In the case where the value is defined there will be stress on the ending.

Each box represents a node in the hierarchy, which also allows for multiple inheritance (represented by horizontal arrows in the figure). For the sake of exposition, we represent each node with four rows and two columns, the lefthand column containing paths of varying degrees of specificity. The requisite features are those for number and case. Case is more specific information than number. For instance, at the node STRESS Bii, $\langle\mathbf{s g}$ acc $\rangle$ is an extension of the path $\langle\mathbf{s g}\rangle$ and therefore more specific. It overrides the value for the path $\langle\mathrm{sg}$ acc $\rangle$ at STESSS Bi, from which the node STRESS Bii inherits all other information, including the path $\langle\mathbf{s g}\rangle$ and any other of its possible extensions. Of course, the path $\langle\mathbf{s g}$ acc $\rangle$ is not specified at the node STRESS Bi, because it is an extension of the path $\langle\mathbf{s g}\rangle$ and will therefore have the same value as the path $\langle\mathbf{s g}\rangle$ at this node. The fact that number comes first in the path is of theoretical significance, indicating that the number distinction is of greater importance in the nominal stress system.

The first and second rows give the most general information; only the attributes sg and pl are given, as more specific information is not required. This reflects the fact that only the nominative plural and accusative singular may deviate. Rows 3 and 4 are used to show the path-value pairings for nominative plural and accusative singular ( $\mathrm{pl}$ nom and $\mathrm{sg}$ acc). Although we could add further rows for the other cases, nothing

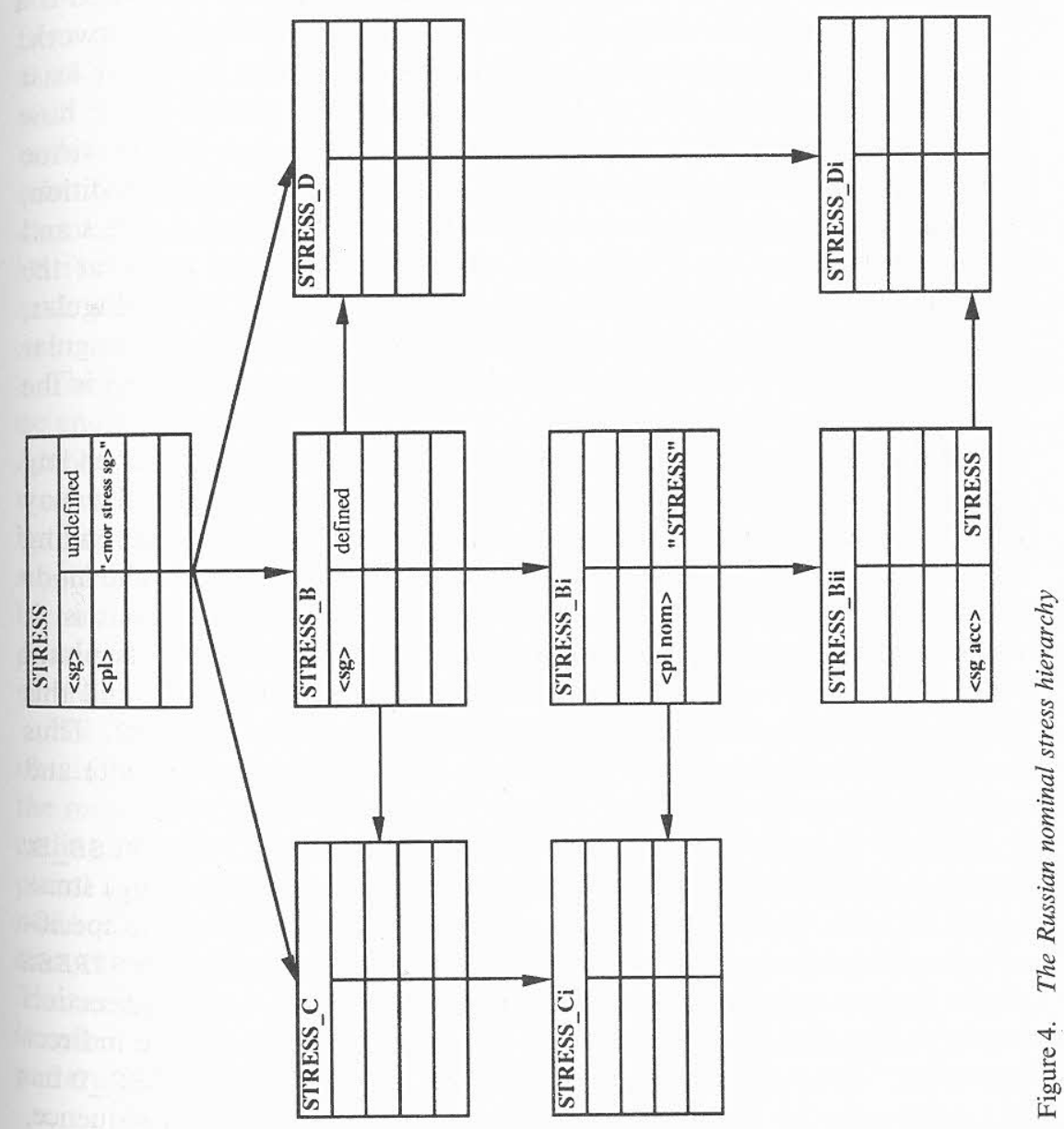


else need be given, as these will be the same as the least specific instances for each number. Quoted paths are indirection markers indicating global inheritance (see section 3), as in the DATR formalism. ${ }^{10}$

Examining Figure 4 in detail we see that at the node STRESS the singular is undefined. This means that there is no ending stress in the singular. The plural is determined by indirect reference to the path "〈mor stress sg $\rangle "$. This is because the path indirectly referenced is a sequence of attributes gathered up across the morphological network. The mor attribute originates in the word-class hierarchy and is the least specific instance of the path for inflection. In the next section we see how the stress hierarchy ties into the declension hierarchy, and it is by virtue of this relation that we reference the whole attribute structure. In addition, we make a distinction between this paradigmatic function of stress and its metrical phonological realization. The generalizations made at the node STRESS are therefore that there is no ending stress in the singular, and that for the plural, stress is evaluated relative to whatever the singular stress may be. This encodes the fact that, by default, plural stress is the same as the singular.

For the node STRESS_B the singular is defined. That is, it has ending stress. As the plural is by default the same as whatever the singular may be, the plural also has ending stress. In this way pattern B has ending stress both in the singular and (by default) in the plural. The node STRESS C has STRESS as its main source of inheritance. That is, it could inherit everything from STRESS. However, it inherits its plural from STESSS B - note the arrow between the two boxes - and this path overrides the information about the plural from STRESS. Thus pattern $\mathrm{C}$ has stem stress in the singular (by the general default) and ending stress in the plural.

STRESS D is stipulated to inherit its singular stress from STRESS_B, which is defined, and therefore STRESS_D has defined (i.e. ending) stress in the singular. STRESS D gets its plural by an evaluation of the specification "〈mor stress sg $\rangle$ ". The node STRESS_D has the node STRESS as its main source of inheritance. In addition, the use of indirection markers to quote the node STRESS forces an evaluation of the indirect reference "〈mor stress sg >" at the node STRESS (i.e. STRESS_D has the same value for plural stress as the node STRESS). As a consequence, plural stress is undefined (i.e. not on the ending). In this way pattern D derives ending stress in the singular and stem stress in the plural. A similar indirect reference is used for the more specific path 〈pl nom $\rangle$ at STRESS_Bi. This path is also evaluated at the node STRESS. Being a more specific instance of the plural, it will also be evaluated as a more specific instance of the 〈mor stress sg > path at STRESS, thus giving an undefined value (i.e. no ending stress) for the plural nominative. If there were no quoted relation with STRESS, the plural nominative would be taken to be indirectly referenced to 〈mor stress sg > at the node STRESS_Bi, thereby giving defined (i.e. ending) stress in the nominative plural, and being no different from STRESS_B. The node STRESS_Ci also inherits this reference via STRESS_Bi and therefore has no ending stress in the plural nominative. The node STRESS_Bii inherits all facts from STRESS_Bi, except that its singular accusative is the same as that at the node STRESS. As $\langle\mathbf{s g}$ acc $\rangle$ is a more specific instance of the path $\langle s g\rangle$, it will have the same value as this path at STRESS (i.e. undefined, or no ending stress). All other facts regarding the singular are inherited from STRESS_Bi, and as this node does not override any facts about the singular that it inherits, the other facts involving the singular attribute are the same at STRESS_Bii as they are at STRESS B. The node STRESS_Di inherits all facts from STRESS_D except its singular accusative, which it gets from STRESS_Bii.

The generalizations at the node STRESS are that the singular will have no ending stress and that the plural is by default the same as the singular. Attribute ordering also allows for the other, apparently contradictory, tendency for number to be distinguished. As the number feature occurs before the more specific case feature, the deviations in the accusative singular and nominative plural are seen as marked. The beauty of the hierarchy is that it requires very little to be specified, the rest being provided by inheritance. Once the various nodes have inherited the appropriate values, the hierarchy is as in Figure 5.

The hierarchy also gives insight into the markedness relations that obtain between the various stress patterns. The highest node represents the most common fact about nouns: that they do not have stress on the ending. Further, the generalization that stress will be the same in the plural as in the singular is also inherited by the node STRESS_B. As this node only overrides "higher" information in one respect, it is less marked than the others that appear to be at its level, STRESS_C and STRESS_D. Those nodes "lower" down are considered to be even more marked. This is reflected in the priority that each declension class has for each stress pattern.

\subsection{The relationship between hierarchies}

The morphological stress system obviously does not exist in a vacuum. In this section we illustrate how the morphological stress and declensional systems are bound together. 


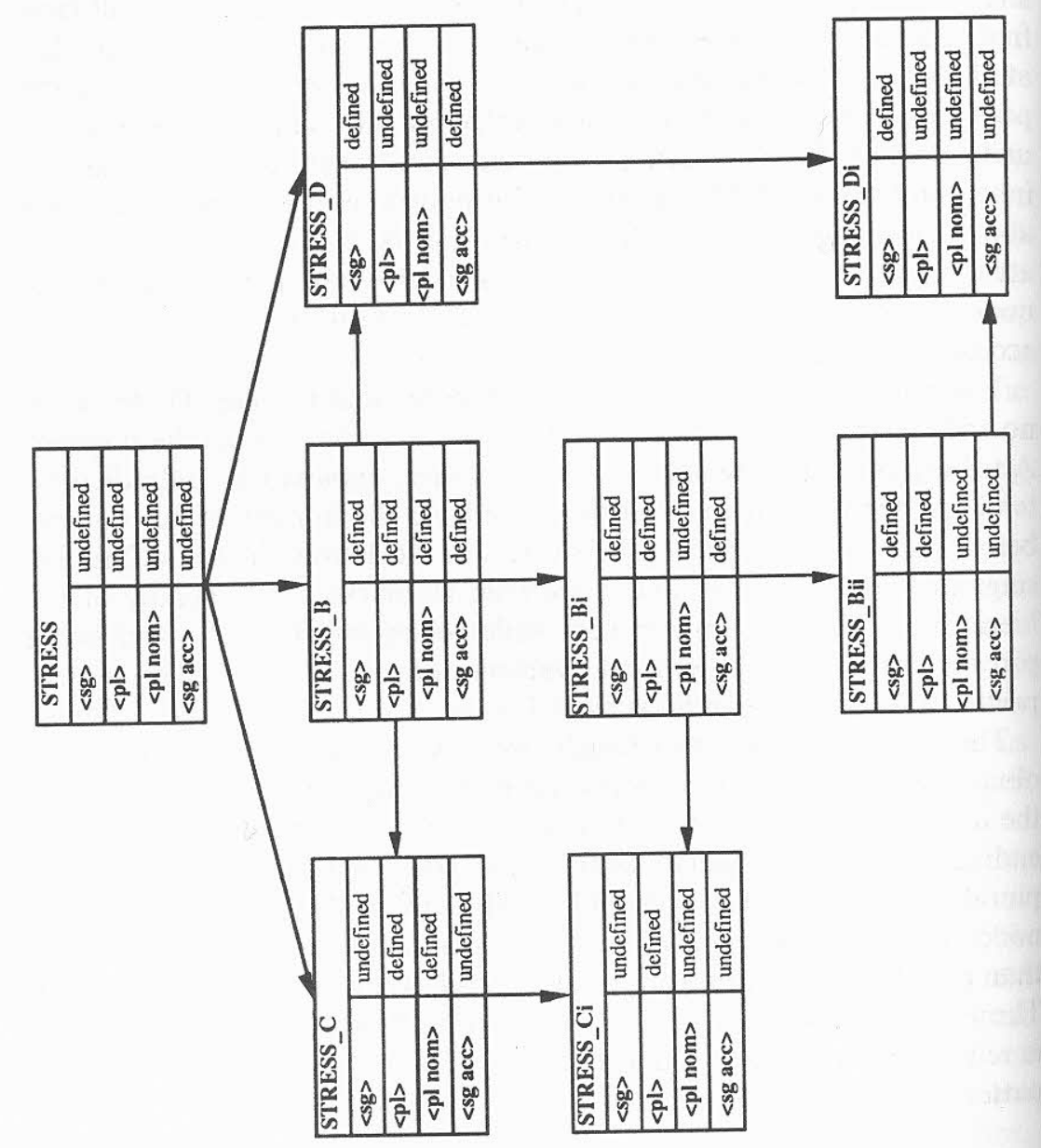

Network morphology provides for a word-class hierarchy that gives the relevant semantic, syntactic, and form information for a given lexeme. Extensions of the form path $\langle$ mor $>$ at the Noun node are to be found by going to the relevant declension node (see Fraser and Corbett 1995); in other words, extensions of this path give the inflectional morphology. Other information, such as the semantics, might determine declension class, otherwise this is specified at the lexical entry. Figure 6 illustrates connections between the word-class hierarchy (where the attribute mor originates) and the declension hierarchy.

In the DATR representation of our network morphology analysis, the word-class hierarchy, which is the main source of inheritance for lexical entries, addresses the appropriate node in the declension hierarchy for morphological information ([12]). Nouns are addressed to the appropriate declension on the basis of semantic and phonological information ([12j]), as in Fraser and Corbett (1995). What is stated at (12i) and $(12 \mathrm{j})$ is, in effect, that more specific instances of the $\langle$ mor $\rangle$ path are to be found at a particular node in the declension hierarchy. For adjectives the situation is more straightforward in that extensions of their morphology are all found at the MOR_ADJ node in the declension hierarchy $([12 \mathrm{f}]){ }^{11}$

\section{(12) NOMINAL:}

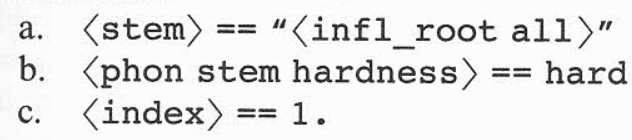

In the word class hierarchy the value for the $\langle$ index $\rangle$ path is 1 ([12c]). As its name indicates, the index attribute is a kind of address that is specifically used by the morphological stress system. In effect, it serves as a form of paradigm index. It is used in the declension hierarchy to 


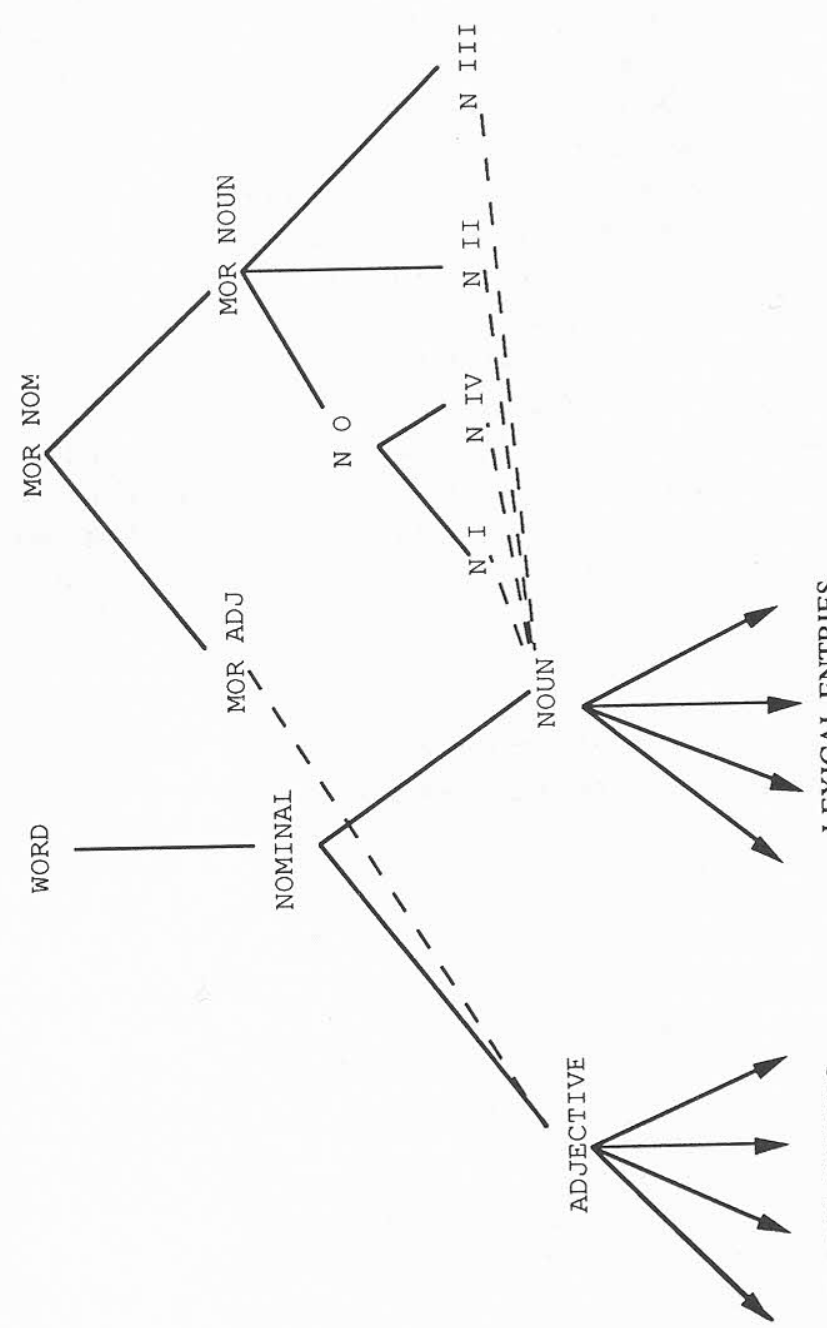

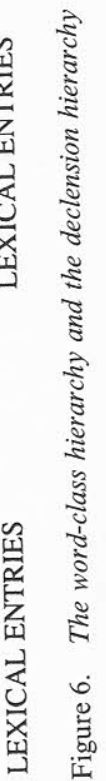

determine the stress pattern to be inherited by a particular lexical entry. This value is inherited by default by each lexical entry, and it can only be overridden at a lexical entry. The indices are chosen to reflect by and large the preference of accentual patterns, but as address values, the indices are arbitrary.

As indicated in section 2.3, the differences between the first, second, and third choices of stress pattern are clearcut for each declension. With the less well represented choices we cannot make a strong claim on the basis of small differences between each of the lower ranked choices. This is why the indices should be understood as paradigm addresses. ${ }^{12}$

However, it is not possible for the default index value to be overridden by any arbitrary value. This is because the index is evaluated in the declension hierarchy to determine from which stress node it should inherit. If a lexical entry is provided with an index that is not found at, or inherited by, a given declension node in the declension hierarchy, the index is useless and no stress information can be inherited, because the node cannot be addressed. Most importantly, the indexical values correspond to the ranking for a given declension (as in Table 3). The index inherited by the lexical entry from the word-class hierarchy, or stipulated at the lexical entry, is evaluated at the node MOR_NOM ([13b]), with the mor attribute prefixed at the beginning of the path, as the addressing determines information that is an even more specific instance of the morphological path. As we move down the rankings (see Table 3 ) the indices for a given declension differ. In virtue of this the specification of apparently the same index at lexical entries belonging to different declensions may well force inheritance from different stress nodes. This is because each declension specifies stress patterns for any index that is not of the first or second rank (shared by nominals [13c] and [13d]). A noun belonging to declension II, for instance if it has an index value 4, will inherit its morphological stress information from the node STRESS_Bi, whereas overriding the index value for a declension I noun would lead to the inheritance of information from the node STRESS_Ci (see Table 3). This means that the stress hierarchy is parasitically indexed by the declension hierarchy. In this way the range of possible stress patterns that a noun, or adjective, could have is delimited by its membership of a particular declension. This is important as it therefore characterizes the differences in stress pattern as constrained by a lexical item's membership of a given declension class.

Figure 7 represents the inheritance relationships between the stress hierarchy and the declensional hierarchy, with numbered dashed lines indicating the index ranking of stress nodes for each declension class (see also [13c] and [13d] below). ${ }^{13}$ The indices address the stress hierarchy as 


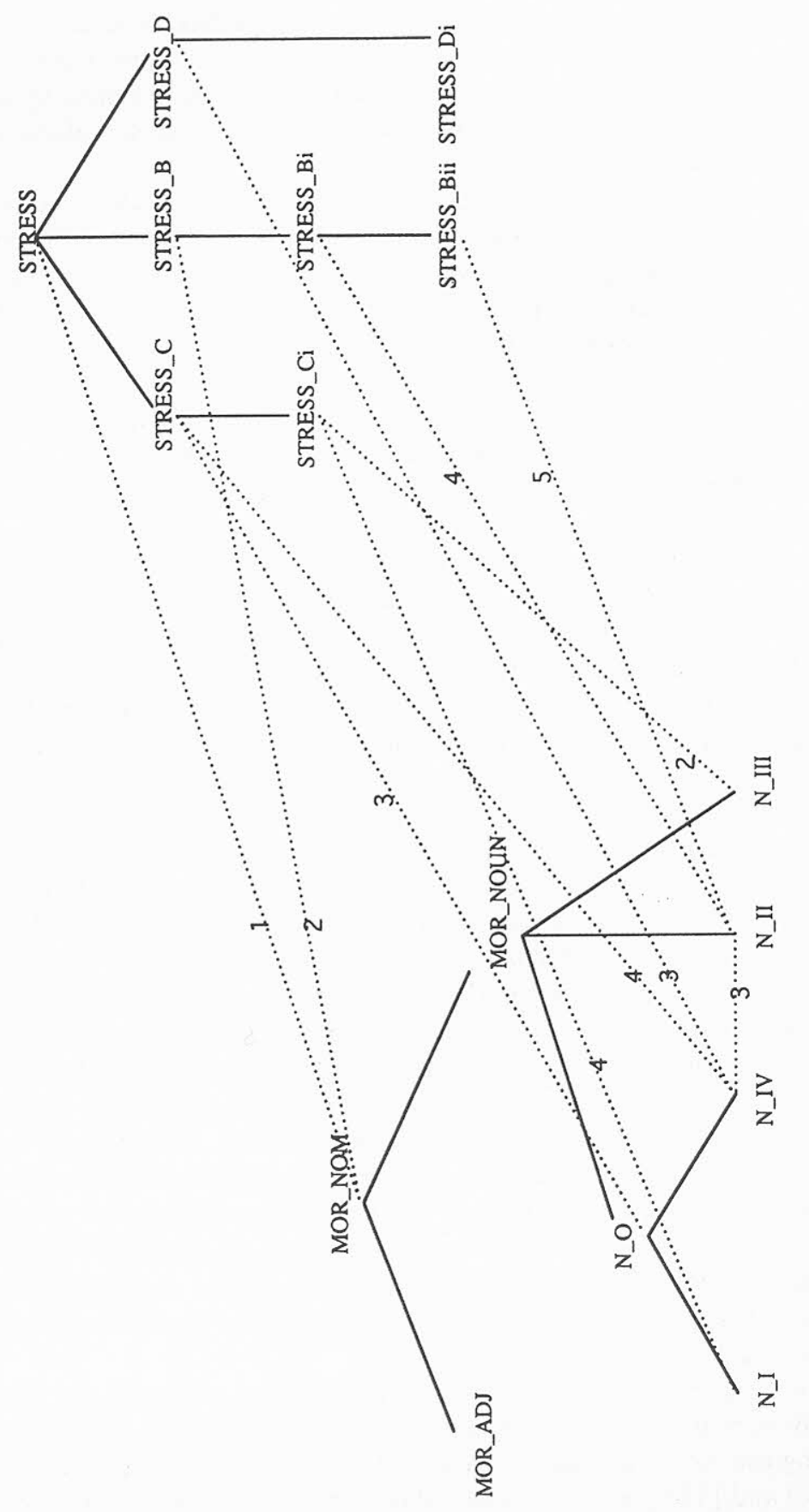

sources of information for more specific instances of the path <mor stress $\rangle$, where the mor attribute originates in the word-class hierarchy, and the stress attribute in the declension hierarchy. The stress hierarchy then extends these in terms of number and, possibly, case. ${ }^{14}$ In this respect the patterns defined in the stress hierarchy can be understood as parasitic paradigms.

At the node MOR_NOM, the nominal node in the declension hierarchy, morphological stress is determined by evaluating the path index, as in (13b), where the atom mor at the beginning of the path indicates that any information evaluated in this way will be more specific instances of the inflectional morphology, accessed in the first instance via the wordclass hierarchy. By default, the index will have the first rank value, 1 ([12c]), and any extensions of the path 〈mor stress > will be found at the top node in the stress hierarchy (Figure 4), the node STRESS ([13c]). This accounts for the default pattern, pattern A. This information is generalized for nouns and adjectives, and this means that it will not need to be specified in the lexical entry for any nominal that has this pattern. ${ }^{15}$ Nominals can also access pattern B, where stress always appears on the ending ([13d]). This is the second choice for all nominals except nouns of declension III.

(13) MOR NOM:

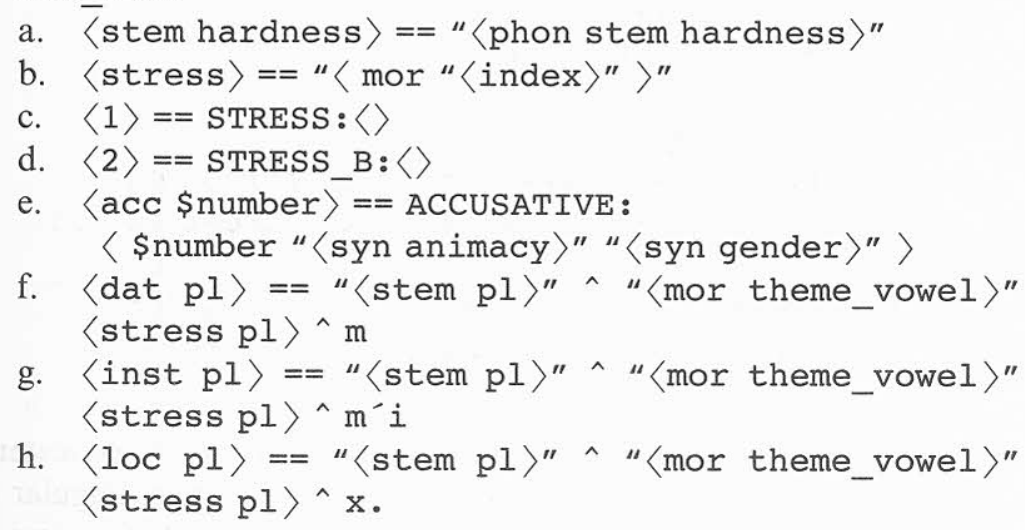

Statements at the node MOR NOM, and all other nodes in the declension hierarchy, consist of a path on the lefthand side with a sequence on the righthand side. This sequence is a concatenation of the values that realize that attribute structure. The value for ending stress is taken to be part of this concatenation. For instance, the path 〈inst pl〉 is realized by concatenating the stem with the ending and the value for plural stress $([13 g])$. 
In (14) the node MOR_NOUN declares those facts that are general for all noun declensions. All other facts are, of course, inherited from the node MOR_NOM.

(14) MOR_NOUN :

$$
\begin{aligned}
& \text { a. } \overline{\langle}\rangle==\mathrm{N} \text { NOM } \\
& \text { b. }\langle\text { loc } s g\rangle=="\langle\text { stem } s g\rangle " \wedge \text { e }\langle\text { stress } s g\rangle \\
& \text { c. }\langle\text { nom pl }\rangle=="\langle\text { stem pl }\rangle " \wedge i\langle\text { stress pl nom } \\
& \text {-.. }
\end{aligned}
$$

In (14c) the path 〈stress pl nom〉 allows for possible variation in the value for stress in the nominative plural, although this possibility is usually not realized. Lower still in the hierarchy is the node N_II ([15]). Here the path 〈nom sg , for example, is realized by concatenating the stem with the ending and the value for stress $([15 \mathrm{~h}])$. (15b)-(15f) are declarations of the possible rank indices for declension class II. (15b) indicates that the third choice for class II is the same as the third choice for class IV.

(15) N_II:

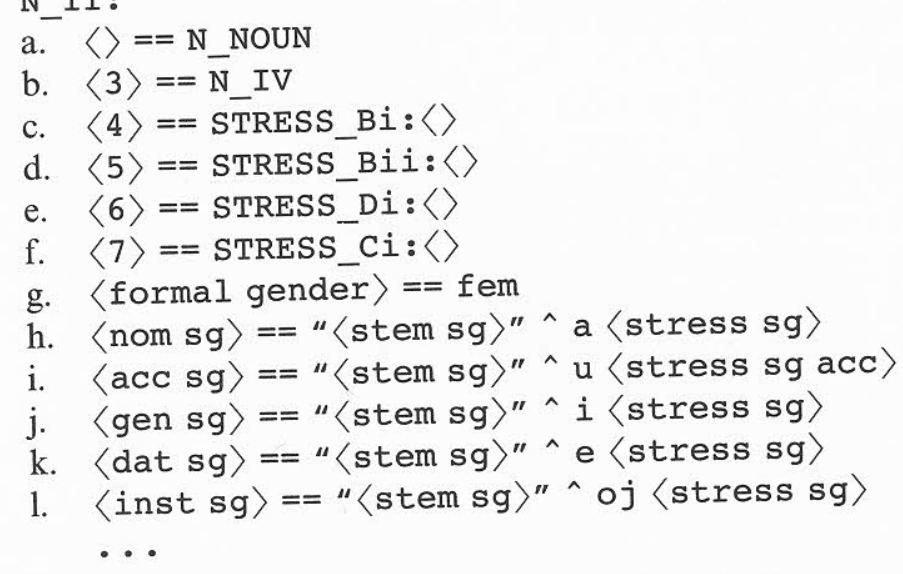

Declension II has a nonsyncretic accusative and this is the concatenation of the stem, the ending, and the value for accusative singular stress ([15i]). As defined in the stress hierarchy in Figure 4, the $\langle\mathbf{s g}$ acc $\rangle$ extension of the path $\langle\mathbf{s g}\rangle$ will by default be the same as $\langle\mathbf{s g}\rangle$, by virtue of it being an extension of this path. We could, if we wished, specify the other case extensions for the path 〈stress sg〉 ([15h], [15j]-[151]). This would make no difference, as these are nowhere specified in the stress hierarchy and, as extensions of the path 〈stress sg $\rangle$, have the same value. The principle is the same for the other nodes in the declension hierarchy, which can be inspected in the Appendixes.
If we take an example lexical entry for a noun, such as kómnata in (16), we see that it is not specified for stress in any way.

\section{(16) Komnata:}

$$
\begin{aligned}
& \langle\rangle==\text { NOUN } \\
& \langle\text { declension_class }\rangle==N_{-} I I:\langle\rangle \\
& \langle\text { gloss }\rangle==\text { room } \\
& \langle\text { infl_root all }\rangle==\text { komnat. }
\end{aligned}
$$

The accusative singular, kómnatu, is the concatenation of the stem komnat, the ending $-u$, and the value for accusative singular stress ([15i]). As the lexical entry is not specified for stress, it will inherit information for its index from the NOUN node, its maximally underspecified source of inheritance in the word-class hierarchy. As the value for index is 1 , this means it will be evaluated to the node STRESS ([13c]) in the stress hierarchy for all extensions of the path 〈mor stress〉, and as all extensions of this path are undefined, including that for the accusative singular (Figures 4 and 5), there is no stress on the ending. The theorem list in (17) gives the values for the case and number combinations of this noun.

(17) Komnata: $\langle$ gloss $\rangle=$ room.

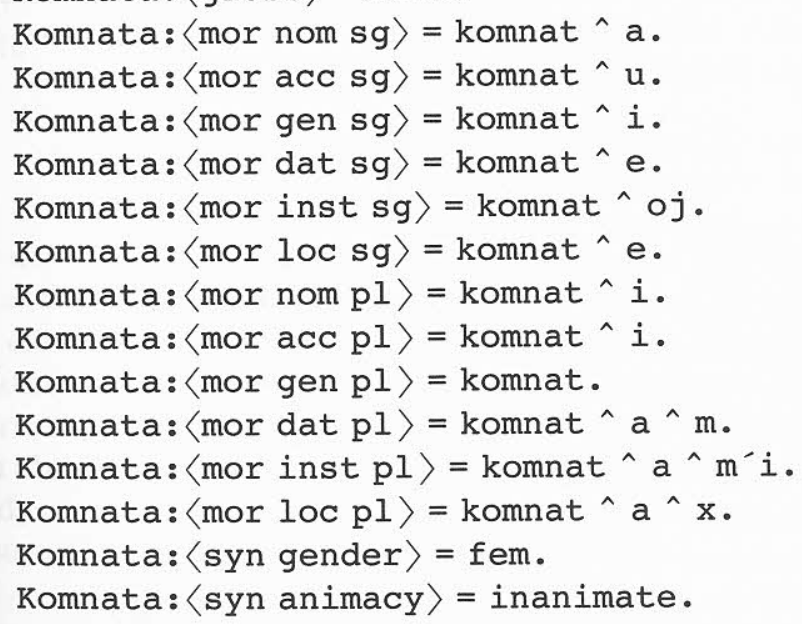

As we assume that the automatic phonology will stress the initial syllable of an unstressed word, the fully inflected forms are left unmarked for stress in this instance. However, with nouns such as zakáz in (18), for example, stress is marked on the root, but with no difference in inheritance information other than that it is a class I noun. ${ }^{16}$ 
(18) Zakaz:

$$
\begin{aligned}
& \langle\rangle=\text { NOUN } \\
& \langle\text { declension_class }\rangle==N_{-} I:\langle\rangle \\
& \langle\text { gloss }\rangle==\text { order } \\
& \langle\text { infl_root all }\rangle==z^{\circ} a^{\circ} \mathrm{z} .
\end{aligned}
$$

An example of a class II noun with a less common stress pattern is borodá, which has pattern Bii, in which both the singular accusative and the plural nominative deviate (see section 2.2). We give the lexical entry for this noun in (19).

(19) Boroda:

$$
\begin{aligned}
& \text { a. }\langle\rangle==\text { NOUN } \\
& \text { b. }\langle\text { declension_class }\rangle==\text { N_II }:\langle\rangle \\
& \text { c. 〈gloss }\rangle==\text { beard } \\
& \text { d. 〈index }\rangle==5 \\
& \text { e. 〈infl_root all }\rangle==\text { borod. }
\end{aligned}
$$

As it overrides the index assignment from the word-class hierarchy ([19d]), borodá is evaluated at the declension class hierarchy to the node STRESS_Bii on the stress hierarchy, and this by virtue of the index rank declaration at the node $\mathrm{N}$ II ([15d]). As the paths $\langle\mathrm{sg}$ acc $\rangle$ and $\langle\mathrm{pl}$ nom $\rangle$ are undefined at this node (indicating no ending stress), and all other possible extensions of $\langle\mathrm{sg}\rangle$ and $\langle\mathrm{pl}\rangle$ are defined, we obtain the theorem list for this noun in (20).

(20) Boroda: $\langle$ gloss $\rangle=$ beard.

Boroda: $\langle\operatorname{mor}$ nom sg $\rangle=$ borod $^{\wedge} \mathrm{a}^{\circ}$ " .

Boroda: $\langle\operatorname{mor}$ acc sg $\rangle=\operatorname{borod}^{\wedge} \mathrm{u}$.

Boroda: $\langle\operatorname{mor} g e n s g\rangle=\operatorname{borod}^{\wedge} i{ }^{\circ} "$.

Boroda: $\langle\operatorname{mor}$ dat $\mathrm{sg}\rangle=\operatorname{borod} \wedge \mathrm{e}^{\circ "}$.

Boroda: $\langle\operatorname{mor}$ inst $s g\rangle=\operatorname{borod}^{\wedge} \circ \mathrm{j}^{\circ} "$.

Boroda: $\langle\operatorname{mor}$ loc $\mathrm{sg}\rangle=\operatorname{borod}^{\wedge} \mathrm{e}^{\circ "}$.

Boroda: $\langle\operatorname{mor}$ nom $\mathrm{pl}\rangle=$ borod $^{\wedge} i$.

Boroda: $\langle\operatorname{mor}$ acc pl $\rangle=\operatorname{borod} \wedge i$.

Boroda:〈mor gen pl> borod $\circ "$.

Boroda: $\langle\operatorname{mor}$ dat pl $\rangle=\operatorname{borod} \wedge \mathrm{a}^{\circ " \wedge} \mathrm{m}$.

Boroda: $\langle\operatorname{mor}$ inst $\mathrm{pl}\rangle=\operatorname{borod}^{\wedge} \mathrm{a}^{\circ} " \cdot \mathrm{m}^{\prime} i$.

Boroda: $\langle\operatorname{mor}$ loc pl $\rangle=\operatorname{borod}^{\wedge} \mathrm{a}^{\circ " \wedge} \mathrm{x}$.

Boroda: $\langle$ syn gender $\rangle=$ fem .

Boroda: 〈syn animacy $\rangle=$ inanimate.

Again, we assume that in the case where ending stress is undefined a default phonological rule provides word-initial stress. A crucial point to note is that declension II has a nonsyncretic accusative singular. We shall return to this point in section 4.4 .

\subsection{Word formation and stress}

It would take another paper to discuss and elaborate a network morphology account of the effects of word-formation processes on the placement of stress. Our appeal to a phonological default to provide initial stress when there is no other stress available is, of course, the same stipulation as that of the basic accentuation principle (Kiparsky and Halle 1978; Halle and Vergnaud 1987). In general, in a derived word, stress is always fixed. Further, it is more often than not stem stress. In other words, we expect the resulting stem to evince pattern A or pattern B stress, the two defaults for nominals. Productive word-formation processes choose the default from another network and in principle seek the highest nodes. In fact the choice of pattern B is highly restricted, leaving only pattern A as a productive option.

Zaliznjak (1985) divides affixes involved in word-formation processes into two groups. This division corresponds to other analyses of affixes as either recessive or dominant, and these have usually been treated as cyclicity effects. The suffix dominant $-a n$, for instance, is involved in word-formation processes such as those in (21).

\section{(21) górlo 'throat' gorlán 'bawler' star'ik 'old man' star'ikán 'old boy' golová 'head' golován 'big head'}

For discussion and explanation see Halle (1973), Feldstein (1984), and Halle and Vergnaud (1987: 98). A network morphology approach to the stress effects of word formation would, naturally, be declarative, both stipulating the phonology of the affix (including stress for those affixes that are inherently stressed) and storing information about stress patterns within the network. As a good example of a declarative approach to prosody and word formation, Bleiching (1992) analyzes word stress assignment in German.

\subsection{Network morphology constraints and predictive power}

An analysis grounded within the network morphology framework makes predictions that vary in the degree to which they might hold or be violated. First, we must consider indices and their theoretical validity. 
We discussed the rank choices for each declension in section 2.3. As noted, patterns A and B may occur in any declension class (and, in fact, also occur in the adjective system). The occurrence of the other patterns is restricted to certain declension classes.

The relationship between the stress patterns and declension class cannot be adequately captured if we assume that they arise from the interaction of various rules of stress assignment together with ending morphemes that might differ only in terms of whether they are stressed or subject to certain rules. A noun belonging to class II cannot have stress pattern C, for example, and yet there must be desinences available to nouns of this declension that could allow for this, given that nouns of this declension can occur in both pattern B and pattern A, for example. The use of indices in network morphology captures this fact. ${ }^{17}$ Of course, we have to specify the index for nouns that do not follow the default, stem stress, in the lexical entry, but the indices assigned to each declension class mean that it is not possible for a noun to follow a stress pattern that is not allowed by its declension. This is weakly predictive. A declension II noun evincing, say, pattern $\mathrm{C}$ would undermine the claims of this theory (see Table 3). ${ }^{18}$

Although in the construction of the network it would be possible to stipulate different indices for each class, certain possibilities are ruled out entirely. One possibility is ruled out by a principle of useful information. If we look at declension II, for example, this is the only class that has patterns where the accusative singular can deviate. While the relationship between nodes STESSS Bi and STRESS_Bii in the stress hierarchy is captured by a mother-daughter relationship, the information in STRESS_Bi $i$ is of no use to the other declensions, as their accusative singular is determined by animacy rules accessed via the node MOR_NOM (see [13e] in section 4.2). Therefore connections between such stress nodes and the declension nodes, other than N_II, are ruled out by this, as yet informal, principle.

The animacy correspondences are dealt with in detail in Corbett and Fraser (1993). On the basis of information regarding their animacy and gender ([13e]), nouns, other than class II nouns, inherit information regarding the form of their accusative from the ACCUSATIVE node ([22]).

\section{(22) ACCUSATIVE}

$$
\begin{aligned}
& \text { a. }\langle\text { N number }\rangle=="\langle\operatorname{mor} \text { nom } \$ \text { number }\rangle " \\
& \text { b. }\langle\text { pl animate }\rangle=="\langle\text { mor gen pl }\rangle " \\
& \text { c. }\langle\text { sg animate masc }\rangle=="\langle\text { mor gen sg }\rangle " \text {. }
\end{aligned}
$$

In (22a) we see that for any number, regardless of gender, the accusative is found by indirect reference to the nominative, whatever that may be.
In (22b) the animate plural is the same as whatever the genitive may be. $(22 \mathrm{c})$ is a statement that the masculine singular animate is indirectly referenced to the genitive singular for its value. The effect of this is that only at N II is there an equation for accusative singular, and the accusative plural is globally determined for all declensions on the basis of semantic sex and animacy. Even if we were to extend an arbitrary connection between a declension node other than N_II and the node STRESS_Bii, or STRESS_Di for that matter, it would have no effect, as the override information at STRESS_Bii is of no use to it. The theory therefore makes a prediction about stress related to the rules of animacy. For example, the theory would be shown to be false if a noun of any declension other than class II were to have stress on the stem in the accusative singular when either the nominative singular, if it were inanimate, or the genitive singular, if it were animate, had stress on the ending. The same would also hold of the accusative plural for all declensions. Violations of this claim would fundamentally undermine the theory.

At the same time, however, we are able to characterize the markedness relations in the stress system by looking at the stress hierarchy to one side. Those patterns such as the subpatterns of $\mathrm{B}, \mathrm{Bi}$, and $\mathrm{Bii}$ are characterized as marginal, because they occur lower down in the hierarchy. The same is also true for Di. Equally, we would expect $\mathrm{Ci}$ to decline in popularity. Comrie and Stone (1978: 60) note that nouns such as védomost', belonging to this declension, have innovated to follow the default pattern. As the majority of nouns in class III are accounted for by a highly productive process of word formation with the suffix -ost', and this is probably the only way by which new nouns are added to this class, we would expect only the default pattern A.

The use of attribute extension in the stress hierarchy also brings together another aspect of the Russian noun stress system that has been noted by Comrie and Stone (1978) and others. As the subpatterns override higher information by extending number (singular and plural) with case (accusative and nominative), the markedness of these subpatterns can be connected with the minor tendency for the noun stress system to be a means for further distinguishing singular and plural. This order also reflects the greater relative relevance of the category of number as compared with case, as pointed out by Nesset (1993: 27-28).

\section{Morphological stress and metrical assignment}

In this section we consider the way Russian is dealt with in analyses that make use of metrical assignment of stress. We argue that there is a 
relationship between paradigms and lexical marking. Our approach is not antagonistic to metrical accounts, and we show that the most prominent account of the Russian data does not in essence rely on metrical assignment, but rather on the use of cyclicity. We argue that this appears to require extensive lexical marking in any event.

\section{1. "Mixed" systems, lexical systems, and paradigms}

Building on the works of Liberman (1975) and Liberman and Prince (1977), current metrical approaches, and related analyses, conceive of stress assignment as grounded in a set of parameters, selected according to language, which build syllable-based constituent structure. As has been indicated by Roca (1992: 276), paradigmatic stress presents an "apparent challenge" to such views of stress assignment. This is because in some languages stress does not appear to be determined by the constructing of metrical structure, but rather by the position that a given form occupies within the morphological paradigm. However, a distinction should be made between systems that allow for exceptionality that is constrained because it is lexical, such as the "mixed" system of Macedonian, and so-called lexical systems, such as that of Sanskrit. This then leaves those systems where stress has an apparently paradigmatic role to be accounted for.

\section{2. “Mixed" stress systems}

A "mixed" stress system is mixed in that its regular assignment of stress allows for a limited kind of lexical exceptionality. Macedonian has antepenultimate stress (Comrie 1976; Franks 1987), with exceptional penultimate stress. Detailed explanations are given in Franks (1987) and Halle and Vergnaud (1987). The settings in (23) account for the usual antepenultimate stress. Assigning stress in the lexical entry accounts for the exceptional examples with penultimate stress.

As pointed out in Halle and Vergnaud (1987) and Roca (1992), the settings for stress assignment mean that there is a three-syllable window constraint in Macedonian. The placing of a lexical accent on any morpheme that precedes the last three syllables of a form will have no effect given the algorithm for stress assignment. Roca illustrates with the example vodéničar 'miller'. Putting an arbitrary lexical accent on the first syllable has no effect in generating the correct stress. This would be assigned to the form vodéničar, even if lexical accent were assigned to the wrong pre-antepenultimate syllable. We give the parameter settings for Macedonian in (23) (taken from Roca 1992: 270) and then the example (24), where stress is correctly assigned to the form vodéničar when it has been preassigned "incorrect" lexical stress.

(23) Macedonian stress algorithm parameter settings

extrametricality
head terminal
bound
headedness
directionality
constituent construction
on line 0
on line 1
constituent conflation
lines 1 and 2

$\begin{array}{ll}\text { line } 0 & \text { line } 1 \\ + & - \\ + & + \\ + & - \\ \mathrm{L} & \mathrm{R} \\ \mathrm{R}-\mathrm{L} & \mathrm{n} / \mathrm{a}\end{array}$

The algorithm in (23) will still give the correct stress in (24) (Roca's example 18) despite the unmotivated assignment of lexical stress to the first syllable.

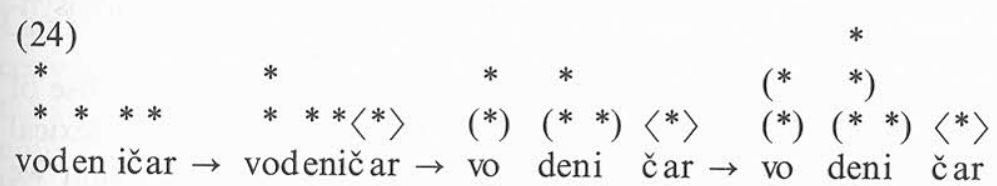

Only when the lexical stress occurs within the three-syllable window from the right edge can it affect the assignment of stress. Thus, it is possible to account for the irregular stress of konzumátor in (25) (Roca's example 13).

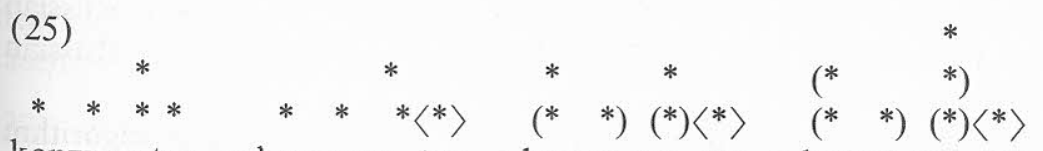

konzumator $\rightarrow$ konzuma tor $\rightarrow$ konzu ma tor $\rightarrow$ konzu ma tor

It should be noted here that the use of bounded constituent assignment on line 0 guarantees that it is not possible for unmotivated lexical stress to break the three-syllable window constraint. Similarly, bounded constituent construction is argued for in Polish, because this better accounts for exceptions in that language (see Halle and Vergnaud 1987: 57). 


\subsection{Lexical systems}

Sanskrit is described by Roca (1992) as a "pure accent system," and Halle and Vergnaud (1987) point out that the use of cyclicity can account for the difference between "dominant" and "recessive" affixes. In the next subsection we go on to consider so-called paradigmatic stress and consider how this compares with totally "lexical" stress. In the next section, we then go on to consider the Russian nominal accentual system.

\subsection{Paradigmatic stress}

A paradigmatic stress system is one in which the placement of stress appears to be determined by the position of a form within the paradigm. Spanish verbal stress, the issue dealt with by Roca (1992), is an example of this. As is apparent from the data in section 2, the situation with Russian is slightly different. On the whole a form will not differ according to its position within the paradigm. The placement of stress will, by default, be the same no matter what the position of the form within the paradigm. Russian nouns show varying degrees of idiosyncrasy in their stress patterns, but, as we have demonstrated in our network morphology analysis, the position of a form within the paradigm is how this idiosyncrasy manifests itself. Stress deviates in terms of number and case.

We consider how our approach compares with one that makes use of cyclicity to derive the correct stress patterns. We then contend that lexical marking of some kind is still required and that the approach that we have outlined is transparent and facilitates later phonological operations.

\section{Metrical accounts of the Russian data}

In this section we consider the metrical assignment of stress to Russian nouns and consider what it tells us about the morphology of the Russian noun system.

We assume the parameter settings for the Russian stress algorithm given in (26), where we follow the format of Roca (1992).

(26) Russian stress algorithm parameter settings

extrametricality

head terminal

bound

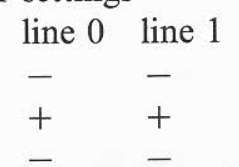

headedness

directionality

R L

constituent construction on line 1

constituent conflation

lines 1 and 2

There can be no extrametricality in Russian, as stress may occur either on the initial syllable or on an ending. Constituents have to be head terminal, because constituent structure is unbounded, and unbounded constituents that are not head terminal would not satisfy the recoverability condition (Halle and Vergnaud 1987: 10-11). Line 0 constituents are right-headed. Halle and Vergnaud (1987: 29) draw this conclusion from evidence based on vowel deletion; stress moves to the left when a stressed vowel is deleted before a full vowel in the following syllable. Line 1 constituents are left-headed as a stipulation of the basic accentuation principle (Kiparsky and Halle 1978; Halle and Vergnaud 1987: 84), where the leftmost accented vowel is stressed, and the leftmost vowel is stressed in the absence of an accented vowel.

Halle and Vergnaud (1987: 98) demonstrate that endings and other suffixes are "invariably cyclic." However, cyclic endings should be stressdeleting. Halle and Vergnaud point out that this is not the case for Russian. They therefore assigned a stress copy rule to the cyclic stratum. Later works (Halle 1990; Halle et al. 1991), in which the stress erasure convention and conflation have been improved, appear to have eliminated the stress copy rule. Bearing this in mind, we consider two examples for nouns in class IV, which has lexemes for all four of the major patterns. We start with the two major patterns, $\mathrm{A}$ and $\mathrm{B}$, and consider what implications there are, for the marking of affixes both in terms of cyclicity, and in terms of the number of desinences that are required.

In (27) we consider the class IV noun blúd-o attached to its nominative singular suffix, which is taken to be cyclic, following Halle and Vergnaud (1987: 98). The algorithm in (26) is applied. It is also assumed that the stem $b l^{\prime} u d$ - has no stress assigned underlyingly to line 1 and that the case/number suffix also has no stress assigned underlyingly.

(27) bl'udo [[bl'ud $]^{\mathrm{c}}$ o $]^{\mathrm{c}}$

$\begin{array}{lll}\text { line } 0 & \left.{ }^{*}\right) & \\ \text { line } 1 & * & \\ \text { line } 0 & * & \left(^{*}\right) \\ \text { line } 1 & & *\end{array}$

Taking the assumptions for (26) above and applying them to the example 
we get *bl'udó. The reason for this is that the stress erasure convention (Halle et al. 1991: 143) erases the stress assigned on the previous cycle. In the second cycle line 1 stress is assigned to the rightmost syllable (to mark the head of line 0 ), as required. This is then the only syllable available for assigning line 2 stress, which is then conflated with line 1 . It appears therefore that a rule of stress copy is required to account for pattern A. Halle and Vergnaud (1987: 98) also indicate that its use accounts for the alternation between initial stress and ending stress as opposed to underlying stem stress (not necessarily stem-initial), which is copied over.

In example (28) we see that no stress copy rule will allow us to derive nouns of stress pattern $\mathrm{B}$, such as vešč estvó.

(28) vešč estvo $\left[\left[\left[\text { vešč }^{\prime}\right]^{c} \text { estv }\right]^{c} \text { o }\right]^{c}$

\begin{tabular}{|c|c|c|}
\hline line 0 & $(*)$ & \\
\hline line 1 & $*$ & \\
\hline line 0 & $*$ & (*) \\
\hline line 1 & & * \\
\hline line & $*$ & $*$ \\
\hline
\end{tabular}

This gives us the correct form veščestvó. However, this means that we have to distinguish between those inflected forms that undergo the rule of stress copy and those that do not. The point to note here is that we have not assumed that the desinence is underlyingly stressed in either case. The difference in stress pattern merely falls out from whether we allow the rule of stress copy to apply. The point is that a stipulation is required that it should, or should not, apply, and the question is WHERE this stipulation is made. The answer to this question is not obvious; nor is it a question that we wish or are able to address directly here. It can be seen that similar questions arise for the other stress patterns.

We have seen that presence or absence of a rule of stress copy could, without the aid of underlying stress on endings or stems, account for a switch between what we have termed patterns A and B. However, such a rule is extremely powerful. If we wished to account for patterns A and $\mathrm{B}$, without making use of the rule of stress copy, it is not clear how we could deal with nouns of pattern A. Equally, for patterns C and D we would require some switch between the singular and plural based on application or nonapplication of stress copy. The only other routes open would be to abandon a switch based on stress copy and to assume either that there are a number of desinences that realize the same morphosyntac- tic features (including gender) and differ only in terms of whether they are stressed or not, or that there are a number of desinences that realize the same morphosyntactic features (including gender) and differ only in terms of whether they are cyclic or not.

The question at hand is not whether we choose to see endings as cyclic or noncyclic. In either instance we will be forced at a certain point to specify that an ending is stressed or cyclic in order to account for all the possible patterns. Once we do this, we are committed to more than one desinence for each case and number combination of a given paradigm (or gender, depending on one's view). If we do this we then have to specify the stem for the desinence that it combines with. In other words, it appears that we would have to mark this lexically. In addition, there would be an increase in desinences. This relates directly to the issue of paradigm economy (see Carstairs 1988). If we also allow for cases where stems may take desinences that differ only in terms of whether they are cyclic or not subject to a rule of stress copy, or whether they are stressed or not, we would need some way of capturing the fact that these desinences are otherwise phonologically identical. Without some such mechanism, the relationship between nouns such as vešč estvó and, say, télo appears to be accidental. The network morphology analysis promoted in this paper captures the phonological identity of desinences and allows for lexical marking of stress in a transparent way, which is also constrained by membership of a particular declension.

\section{Conclusion}

We have argued for a view of the Russian stress system that accepts its partly morphological nature, a fact indicated by the limited positions within the paradigm where stress may deviate. This also accounts for the minor tendency to distinguish number, a fact captured by attribute ordering. Stress assignment in the nominal system is determined by a hierarchy accessed by the declensional network. By default this hierarchy will not define ending stress. This leaves the phonology free to assign its own default, initial, stress. In considering the use of cyclicity to explain these alternations, we pointed out that stems must either be marked for particular desinences that are stressed or not, or have some other lexical marking to indicate that they undergo a rule of stress copy. In our approach there is transparent lexical marking of less general stress, which is still constrained by declension membership. As there is no extra marking of desinences required we are able to capture the fact that desinences that may be either stressed or not stressed are otherwise phonologically the 
same, keeping the declensional system maximally economic (see Carstairs 1988). The treatment of animacy in our analysis also makes it impossible for syncretic accusatives to have different stress from the form with which they are syncretic. It is not clear how other analyses that allow stress patterns to fall out from the marking of endings would account for this. Our analysis can be verified on the basis of the predictions made at the end of section 4. Additionally, by virtue of its encoding in a formally explicit notation for which computer interpreters exist, our analysis can be shown to yield the correct results. The detailed theory appears in Appendix 1, and the automatically derived results for it are given in Appendix 2.

\section{Received 12 December 1994 \\ Revised version received \\ 28 August 1995}

\section{University of Surrey University of California, Berkeley}

\section{Appendix 1. A fragment of a network morphology account of Russian nominal morphology and morphological stress represented in DATR}

All forms are in phonological transcription and not in standard orthography. The symbols ${ }^{\wedge}$ and ${ }^{\circ}$ are to represent concatenation and overlap, where the overlap operator indicates association with the nearest stressbearing unit to the left. The $\backslash$ "symbol combination is to represent stress, where the backslash quotes an otherwise reserved symbol.

\# vars $\$$ number: sg pl.

\# vars \$sex: male female undifferentiated.

\section{Word-class hierarchy}

\section{NOMINAL:}

$\langle$ stem $\rangle==$ "〈infl_root all $\rangle$ "

$\langle$ phon stem hardness $\rangle==$ hard

$\langle$ index $\rangle==1$.

ADJ :

$$
\langle\rangle==\text { NOMINAL }
$$

$\langle$ syn cat $\rangle==\operatorname{adj}$

$\langle$ mor $\rangle==$ MOR_ADJ $:\langle\rangle$.

NOUN :

\langle\rangle$==$ NOMINAL

$\langle$ infl_root final $\rangle==$ consonant $\langle$ mor $\rangle==$ "〈declensional_class $\rangle "$

$\langle$ declensional_class $\rangle==$

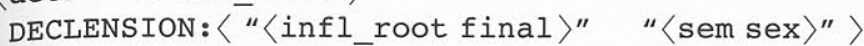

$\langle$ syn cat $\rangle==\mathrm{n}$

$\langle$ sem $\operatorname{sex}\rangle==$ undifferentiated

$\langle$ syn gender $\rangle==$ GENDER: $\langle$ "〈sem sex $\rangle "\rangle$

$\langle$ syn animacy $\rangle==$ " $\langle$ sem animacy $\rangle "$

$\langle$ sem animacy $\rangle==$ ANIMACY $:\langle$ "〈sem sex $\rangle "\rangle$.

\section{Some case switches}

ADJ_VOWEL

$\langle\overline{\rangle}==\backslash \wedge i$

$\langle 0\rangle "\rangle==\backslash \wedge$.

GENDER :

$\langle$ male $\rangle==\operatorname{masc}$

$\langle$ female $\rangle==$ fem

$\langle$ undifferentiated $\rangle==$ "〈mor formal gender $\rangle "$.

ANIMACY :

\langle\rangle$==$ animate

〈undifferentiated $\rangle==$ inanimate.

\section{ACCUSATIVE :}

$\langle$ snumber $\rangle==$ " $\langle$ mor nom $\$$ number $\rangle "$

$\langle\mathrm{pl}$ animate $\rangle==$ "〈mor gen $\mathrm{pl}\rangle$ "

$\langle$ sg animate masc $\rangle=="\langle$ mor gen $\mathrm{sg}\rangle "$.

DECLENSION :

$\langle$ consonant male $\rangle==\mathrm{N}_{-} \mathrm{I}:\langle\rangle$

$\langle$ consonant female $\rangle==$ N_II $:\langle\rangle$

$\langle$ vowel $\$$ sex $\rangle==N_{-}$V: \langle\rangle .

MGP :

\langle\rangle$==$ "〈mor $\rangle "$

$\langle$ soft $\rangle=="\langle$ stem pl $\rangle " \backslash \wedge$ ej "〈mor stress pl $\rangle "$.

STEMSTRESS :

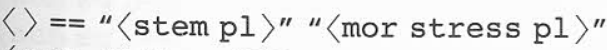

$\left\langle\right.$ soft $\left.\left.{ }^{\circ}\right\rangle "\right\rangle==$ MGP.

Declensional class hierarchy

MOR NOM :

$\langle$ stem hardness $\rangle==$ "〈phon stem hardness $\rangle "$ 
$\langle$ stress $\rangle==$ " $\langle$ mor " $\langle$ index $\rangle "\rangle "$

$\langle 1\rangle==$ STRESS $:\langle\rangle$

$\langle 2\rangle==$ STRESS_B: \langle\rangle

$\langle$ acc number $\rangle==$

ACCUSATIVE: $\langle$ \$number "〈syn animacy $\rangle$ " "〈syn gender $\rangle$ " $\rangle$

$\langle$ dat $\mathrm{pl}\rangle==$

"〈stem pl $\rangle " \backslash \wedge "\langle$ mor theme_vowel $\rangle "\langle$ stress pl $\rangle \backslash^{\wedge} \mathrm{m}$

〈inst pl $\rangle==$

"〈stem pl $\rangle " \backslash \wedge "\langle$ mor theme_vowel $\rangle "\langle$ stress pl $\rangle \backslash \wedge \mathrm{m}^{\prime} i$

$\langle$ loc pl $\rangle==$

"〈stem pl $\rangle " \backslash \wedge "\langle$ mor theme_vowel $\rangle "\langle$ stress pl $\rangle \backslash^{\wedge} \mathrm{x}$.

\section{MOR_NOUN :}

$\langle\overline{\rangle}==$ MOR_NOM

$\langle$ loc sg $\rangle=="\langle$ stem sg $\rangle " \backslash \wedge$ e $\langle$ stress sg $\rangle$

$\langle$ nom pl $\rangle=="\langle$ stem pl $\rangle " \wedge i\langle$ stress pl nom $\rangle$

$\langle$ gen pl $\rangle==$ MGP : $\langle "\langle$ mor stem hardness $\rangle "$ gen pl $\rangle$

$\langle$ theme_vowel $\rangle==\mathrm{a}$.

N_O:

\langle\rangle$==$ MOR_NOUN

$\langle 3\rangle==$ STRESS_C $:\langle\rangle$

$\langle$ gen $s g\rangle==$ "〈stem sg $\rangle " \backslash^{\wedge} a\langle$ stress sg $\rangle$

$\langle$ dat $\mathrm{sg}\rangle=="\langle$ stem $\mathrm{sg}\rangle " \backslash^{\wedge} \mathrm{u}\langle$ stress $\mathrm{sg}\rangle$

$\langle$ inst $\mathrm{sg}\rangle==$ "〈stem $\mathrm{sg}\rangle " \backslash \wedge$ om $\langle$ stress $\mathrm{sg}\rangle$.

N_I :

\langle\rangle$==$ N_O

$\langle 4\rangle==\overline{\text { STRESS_Ci }:\langle\rangle}$

$\langle 5\rangle==$ STRESS D : \langle\rangle

$\langle 6\rangle==$ STRESS_Bi: \langle\rangle

$\langle$ formal gender $\rangle==$ masc

$\langle$ nom sg $\rangle==$ "〈stem sg $\rangle "\langle$ stress sg $\rangle$

$\langle$ hard gen pl $\rangle=="\langle$ stem pl $\rangle " \backslash \wedge$ ov $\langle$ stress pl $\rangle$.

\section{N II:}

\langle\rangle$==$ MOR_NOUN

$\langle 3\rangle==N$ IV

$\langle 4\rangle==$ STRESS $\mathrm{Bi}:\langle\rangle$

$\langle 5\rangle==$ STRESS_Bii: \langle\rangle

$\langle 6\rangle==$ STRESS Di: \langle\rangle

$\langle 7\rangle==$ STRESS_Ci: \langle\rangle

$\langle$ formal gender $\rangle==$ fem

$\langle$ nom $\mathrm{sg}\rangle=="\langle$ stem $\mathrm{sg}\rangle " \backslash \wedge \mathrm{a}\langle$ stress $\mathrm{sg}\rangle$

$\langle$ acc $s g\rangle=="\langle$ stem $\mathrm{sg}\rangle " \backslash \wedge \mathrm{u}\langle$ stress $\mathrm{sg}$ acc $\rangle$

$\langle$ gen $\mathrm{sg}\rangle=="\langle$ stem $\mathrm{sg}\rangle " \backslash^{\wedge} i\langle$ stress $\mathrm{sg}\rangle$

$\langle$ dat $\mathbf{s g}\rangle=="\langle$ stem $\mathbf{s g}\rangle " \backslash \wedge \mathrm{e}\langle$ stress $\mathbf{s g}\rangle$ $\langle$ inst $s g\rangle=="\langle$ stem $s g\rangle " \backslash \wedge \circ j\langle$ stress sg $\rangle$

$\langle$ gen $\mathrm{pl}\rangle==$ STEMSTRESS : $\langle$ "〈mor stem hardness $\rangle "\langle$ stress pl $\rangle$.

N_III:

\langle\rangle$==$ MOR NOUN

$\langle 2\rangle==$ STRESS_Ci: \langle\rangle

$\langle 3\rangle==$ STRESS_B $:\langle\rangle$

$\langle$ formal gender $\rangle==$ fem

$\langle$ stem hardness $\rangle==$ soft

$\langle$ nom sg $\rangle==$ N I

$\langle$ gen $s g\rangle==N_{-} I I$

$\langle$ dat $\mathrm{sg}\rangle==$ "〈mor gen $\mathrm{sg}\rangle "$

inst $\mathrm{sg}\rangle=="\langle$ stem $\mathrm{sg}\rangle " \backslash \wedge$ ju

$\langle l$ loc $\mathrm{sg}\rangle==$ "〈mor dat $\mathrm{sg}\rangle "$.

N_IV:

\langle\rangle$==$ N_O

$\langle 3\rangle==$ STRESS_D $:\langle\rangle$

$\langle 4\rangle==$ STRESS_C $:\langle\rangle$

$\langle 5\rangle==$ STRESS_Bi: \langle\rangle

$\langle 6\rangle==$ STRESS_Ci: \langle\rangle

$\langle$ formal gender $\rangle==$ neut

$\langle$ nom sg $\rangle=="\langle$ stem sg $\rangle " \backslash \wedge 0\langle$ stress sg $\rangle$

$\langle$ nom pl $\rangle==$ "〈stem pl $\rangle " \backslash \wedge$ a $\langle$ stress pl nom $\rangle$

$\langle$ gen $\mathrm{pl}\rangle==\mathrm{N}$-II.

N V :

\langle\rangle$==$ "〈infl_root all $\rangle "$

$\langle$ formal gender $\rangle==\langle$ "〈sem animacy $\rangle "\rangle$

$\langle$ animate $\rangle==$ masc

$\langle$ inanimate $\rangle==$ neut .

Adjectives

MOR_ADJ :

\langle\rangle$==$ MOR_NOM

$\langle$ nom sg fem $\rangle=="\langle$ stem sg $\rangle " \backslash \wedge a\langle$ stress $s g\rangle \backslash \wedge j a$

$\langle$ nom sg neut $\rangle=="\langle$ stem sg $\rangle " \backslash \wedge 0\langle$ stress $s g\rangle \backslash \wedge e$

$\langle$ nom sg $\rangle==$

"〈stem sg $\rangle "$ ADJ_VOWEL: $\langle\langle$ stress sg $\rangle\rangle\langle$ stress $s g\rangle \backslash \wedge j$

$\langle$ acc sg fem $\rangle=="\langle$ stem $s g\rangle " \backslash \wedge u\langle$ stress $s g\rangle \backslash \wedge j u$

$\langle$ gen $\mathrm{sg}$ fem $\rangle=="\langle$ stem $\mathrm{sg}\rangle " \backslash^{\wedge} \circ\langle$ stress $\mathrm{sg}\rangle \backslash^{\wedge} j$

$\langle$ gen $\mathrm{sg}\rangle==$

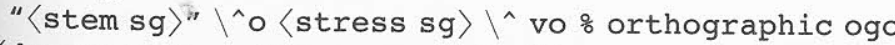

$\langle$ dat $\mathrm{sg}$ fem $\rangle==$ "〈mor gen sg fem $\rangle "$

$\langle$ dat $\mathrm{sg}\rangle=="\langle$ stem $\mathrm{sg}\rangle " \backslash \wedge \mathrm{o}\langle$ stress $\mathrm{sg}\rangle \backslash \wedge \mathrm{mu}$ 
$\langle$ inst sg fem $\rangle==$ "〈mor gen sg fem $\rangle "$

$\langle$ inst $s g\rangle=="\langle$ stem $s g\rangle " \backslash^{\wedge} i\langle$ stress $s g\rangle \backslash^{\wedge} \mathrm{m}$

$\langle$ loc sg fem $\rangle=="\langle$ mor gen sg fem $\rangle "$

$\langle$ loc $\mathrm{sg}\rangle=="\langle$ stem $\mathrm{sg}\rangle "\rangle^{\wedge} \mathrm{O}\langle$ stress $\mathrm{sg}\rangle \backslash^{\wedge} \mathrm{m}$

$\langle$ theme_vowel $\rangle==i$

$\langle$ nom pl $\rangle==$

"〈stem pl $\rangle " \backslash \wedge "\langle$ mor theme_vowel $\rangle "\langle$ stress pl $\rangle \backslash^{\wedge} \mathrm{e}$ $\langle$ gen pl $\rangle=="\langle$ mor loc pl $\rangle "$

$\langle$ acc $\rangle==$ ACCUSATIVE $:\langle\rangle$.

Stress hierarchy

STRESS :

\langle\rangle$==$

. $\langle\mathrm{pl}\rangle==$ "〈mor stress sg $\rangle "$.

STRESS_B:

$$
\begin{aligned}
& \langle\rangle==\text { STRESS } \\
& \langle\mathrm{pl}\rangle==\langle\mathrm{sg}\rangle \\
& \langle\mathrm{sg}\rangle==0\rangle " .
\end{aligned}
$$

STRESS_C :

$$
\langle\rangle==\text { STRESS }
$$

$\langle\mathrm{pl}\rangle==$ STRESS_B.

STRESS_D:

\langle\rangle$==$ "STRESS"

$\langle s g\rangle==$ STRESS_B.

STRESS_Bi:

\langle\rangle$==$ STRESS_B

$\langle$ pl nom $\rangle==$ "STRESS" .

\section{STRESS_Bii:}

\langle\rangle$==$ STRESS_Bi

$\langle$ sg acc $\rangle==$ STRESS .

\section{STRESS_Ci:}

\langle\rangle$==$ STRESS_C

$\langle\mathrm{pl}$ nom $\rangle==$ STRESS_Bi.

\section{STRESS Di:}

\langle\rangle$==$ STRESS_D

$\langle$ sg acc $\rangle==$ STRESS_Bii.

\section{Example lexical entries}

Noun entries

Bol' :

\langle\rangle$==$ NOUN

$\langle$ declensional_class $\rangle==\mathrm{N}$ III $:\langle\rangle$

$\langle$ gloss $\rangle==$ pain

$\langle$ infl_root all $\rangle==\mathrm{bol}^{\prime}$.

Boloto:

\langle\rangle$==$ NOUN

$\langle$ declensional_class $\rangle==$ N_IV $:\langle\rangle$

$\langle$ gloss $\rangle==$ swamp

$\langle$ infl_root all $\rangle==$ bolo $0^{\circ} \backslash t$.

Boroda:

\langle\rangle$==$ NOUN

$\langle$ declensional_class $\rangle==$ N_II $:\langle\rangle$

$\langle$ gloss $\rangle==$ beard

$\langle$ infl_root all $\rangle==$ borod

$\langle$ inde $\bar{x}\rangle==5$.

Ć'erta:

\langle\rangle$==$ NOUN

$\langle$ declensional_class $\rangle==N_{\text {NII }}:\langle\rangle$

$\langle$ gloss $\rangle==$ charateristic

$\langle$ infl_root all $\rangle==\check{c}^{\prime}$ ert

$\langle$ index $\rangle==2$.

Dira:

\langle\rangle$==$ NOUN

$\langle$ declensional_class $\rangle==N_{-} I I:\langle\rangle$

$\langle$ gloss $\rangle==$ hole

$\langle$ infl_root all $\rangle==\operatorname{dir}$

$\langle$ index $\bar{x}==3$.

Dol' a :

\langle\rangle$==$ NOUN

$\langle$ declensional_class $\rangle==$ N_II $:\langle\rangle$

$\langle$ gloss $==$ portion

$\langle$ infl_root all $\rangle==$ dol

$\langle$ phon stem hardness $\rangle==$ soft

〈index $\rangle==7$.

Duša:

\langle\rangle$==$ NOUN

$\langle$ declensional_class $\rangle==$ N II $:\langle\rangle$

$\langle$ gloss $\rangle==$ soul 
$\langle$ infl_root all $\rangle==$ duš $\langle$ mor stem hardness $\rangle==$ soft $\langle$ index $\rangle==6$.

\section{Komnata:}

\langle\rangle$==$ NOUN

$\langle$ declensional_class $\rangle==$ N_II $:\langle\rangle$

$\langle$ gloss $\rangle==$ room

$\langle$ infl_root all $\rangle==$ komnat .

Kon

\langle\rangle$==$ NOUN

$\langle$ declensional_class $\rangle==$ N_I $:\langle\rangle$

$\langle$ gloss $\rangle==$ horse

$\langle$ infl_root all $\rangle==\mathrm{kon}^{-}$

$\langle$ phon stem hardness $\rangle==$ soft

$\langle$ sem animacy $\rangle==$ animate

$\langle$ index $\rangle==6$.

\section{Mesto:}

\langle\rangle$==$ NOUN

$\langle$ declensional_class $\rangle==$ N_IV $:\langle\rangle$

$\langle$ gloss $\rangle==$ place

$\langle$ infl_root all $\rangle==$ mest

$\langle$ index $\rangle==4$.

\section{Mozg:}

$$
\langle\rangle==\text { NOUN }
$$

$\langle$ declensional_class $\rangle==$ N_I $:\langle\rangle$

$\langle$ gloss $\rangle==$ brain

$\langle$ infl_root all $\rangle==\operatorname{mozg}$

$\langle$ index $\bar{x}==3$.

\section{Plošč ‘ad':}

\langle\rangle$==$ NOUN

$\langle$ declensional_class $\rangle==N$ N_III $:\langle\rangle$

$\langle$ gloss $\rangle==$ city_square

$\langle$ infl_root all $\rangle==$ plošč ${ }^{\prime}$ ad $^{\prime}$

$\langle$ phon stem hardness $\rangle==$ soft

$\langle$ index $\rangle==2$.

\section{Skovoroda:}

\langle\rangle$==$ NOUN

$\langle$ declensional_class $\rangle==$ N_II $:\langle\rangle$

$\langle$ gloss $\rangle==$ frying_pan

$\langle$ infl_root all $\rangle==$ skovorod

$\langle$ index $\rangle==4$.
S'olo:

$$
\begin{aligned}
& \langle\rangle==\text { NOUN } \\
& \langle\text { declensional_class }\rangle==N \text { IV }:\langle\rangle \\
& \langle g l o s s\rangle==v i l \text { lage } \\
& \langle\text { infl_root all }\rangle==s^{\prime} \text { ol } \\
& \langle\text { index }\rangle==3 .
\end{aligned}
$$

Stol:

\langle\rangle$==$ NOUN

$\langle$ declensional_class $\rangle==$ N_I $:\langle\rangle$

$\langle$ gloss $\rangle==$ table

$\langle$ infl root all $\rangle==$ stol

$\langle$ index $\rangle==2$.

\section{Vešč estvo:}

\langle\rangle$==$ NOUN

$\langle$ declensional_class $\rangle==$ N_IV $:\langle\rangle$

$\langle$ gloss $\rangle==$ substance

$\langle$ infl_root all $\rangle==$ vešc̆ $^{\prime}$ estv

$\langle$ index $\rangle==2$.

\section{Zakaz :}

\langle\rangle$==$ NOUN

$\langle$ declensional_class $\rangle==\mathrm{N} I \mathrm{I}:\langle\rangle$

$\langle$ gloss $\rangle==$ order

$\langle$ infl_root all $\rangle==z_{\text {aka }}{ }^{\circ} \backslash \mathrm{z}$.

Zub:

\langle\rangle$==$ NOUN

$\langle$ declensional_class $\rangle==N_{-} I:\langle\rangle$

$\langle$ gloss $\rangle==$ tooth

$\langle$ infl_root all $\rangle==\mathrm{zub}$

$\langle$ index $\rangle==4$.

Adjective entries

Molodoj:
\langle\rangle$==A D J$

$\langle$ gloss $\rangle==$ young

$\langle$ infl_root all $\rangle==\operatorname{molod}$

$\langle$ index $\bar{x}==2$.

Novij:

\langle\rangle$==\mathrm{ADJ}$

$\langle$ gloss $\rangle==$ new

$\langle$ infl_root all $\rangle==$ nov . 
Appendix 2. DATR theorems from a network morphology account of Russian nominal morphology and morphological stress

All forms are in phonological transcription and not in standard orthography. The symbols ${ }^{\wedge}$ and ${ }^{\circ}$ are to represent concatenation and overlap, where the overlap operator indicates association with the nearest stressbearing unit to the left. The " symbol is to represent stress.

$\mathrm{BOl}^{\prime}$ : $\langle$ gloss $\rangle=$ pain .

$\mathrm{Bol}^{\prime}$ : $\langle$ mor nom sg $\rangle=\mathrm{bol}^{\prime}$.

$\mathrm{Bol}^{\prime}:\langle\operatorname{mor}$ acc sg $\rangle=\mathrm{bol}^{\prime}$.

$\mathrm{BOl}^{\prime}$ : $\langle\operatorname{mor}$ gen sg $\rangle=\mathrm{bol}^{\prime} \wedge i$.

$\mathrm{Bol}^{\prime}$ : $\langle\operatorname{mor}$ dat $\mathrm{sg}\rangle=\mathrm{bol}^{\prime} \wedge i$.

$\mathrm{Bol}^{\prime}$ : $\langle$ mor inst $\mathrm{sg}\rangle=\mathrm{bol}^{\prime} \wedge$ ju.

$\mathrm{Bol}^{\prime}$ : $\langle\operatorname{mor}$ loc sg $\rangle=\mathrm{bol}^{\prime} \wedge i$.

$\mathrm{Bol}^{\prime}$ : $\langle\operatorname{mor}$ nom pl $\rangle=\mathrm{bol}^{\prime} \wedge i$.

$\mathrm{BOl}^{\prime}:\langle\operatorname{mor}$ acc pl $\rangle=\mathrm{bol}^{\prime} \wedge i$.

$\mathrm{Bol}^{\prime}$ : $\langle$ mor gen pl $\rangle=\mathrm{bol}^{\prime} \wedge$ ej.

$\mathrm{Bol}^{\prime}:\langle\operatorname{mor}$ dat $\mathrm{pl}\rangle=\mathrm{bol}^{\prime} \wedge \mathrm{a}^{\wedge} \mathrm{m}$.

$\mathrm{Bol}^{\prime}:\langle$ mor inst pl $\rangle=\mathrm{bol}^{\prime} \wedge \mathrm{a}^{\wedge} \mathrm{m}^{\prime} i$.

$\mathrm{Bol}^{\prime}:\langle\operatorname{mor}$ loc pl $\rangle=\mathrm{bol}^{\wedge} \wedge \mathrm{a}^{\wedge} \mathrm{x}$.

$\mathrm{Bol}^{\prime}$ : $\langle$ syn gender $\rangle=$ fem .

Bol $^{\prime}$ : $\langle$ syn animacy $\rangle=$ inanimate.

Boloto: $\langle$ gloss $\rangle=$ swamp .

Boloto: $\langle\operatorname{mor}$ nom sg $\rangle=$ bolo ${ }^{\circ} t^{\wedge} 0$.

Boloto: $\langle\operatorname{mor}$ acc $s g\rangle=$ bolo $" t{ }^{\wedge} \mathrm{o}$.

Boloto: $\langle\operatorname{mor}$ gen $\mathrm{sg}\rangle=\mathrm{bol}{ }^{\circ} " \mathrm{t}^{\wedge} \mathrm{a}$.

Boloto: $\langle\operatorname{mor}$ dat $\mathrm{sg}\rangle=\mathrm{bol} 0^{\circ} \mathrm{t}^{\wedge} \mathrm{u}$.

Boloto: $\langle$ mor inst sg $\rangle=$ bolo ${ }^{\circ} t^{\wedge}{ }^{\wedge}$ om .

Boloto: $\langle\operatorname{mor}$ loc sg $\rangle=$ bolo ${ }^{\circ} \mathrm{t}^{\wedge} \mathrm{e}$.

Boloto: $\langle\operatorname{mor}$ nom pl $\rangle=$ bolo ${ }^{\circ} t^{\wedge} a$.

Boloto: $\langle\operatorname{mor}$ acc pl $\rangle=$ bolo ${ }^{\circ} t^{\wedge} a$.

Boloto: $\langle$ mor gen pl $\rangle=$ bolo $" t$.

Boloto: $\langle\operatorname{mor}$ dat $\mathrm{pl}\rangle=\mathrm{bol} 0^{\circ} " \mathrm{t}^{\wedge} \mathrm{a}^{\wedge} \mathrm{m}$.

Boloto: 〈mor inst pl> $=$ bolo ${ }^{\circ} \mathrm{t}^{\wedge} \mathrm{a}^{\wedge} \mathrm{m}^{\prime} i$.

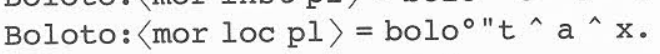

Boloto: $\langle$ syn gender $\rangle=$ neut .

Boloto: $\langle$ syn animacy $\rangle=$ inanimate.

Boroda: $\langle$ gloss $\rangle=$ beard .

Boroda: 〈mor nom sg $\rangle=\operatorname{borod}^{\wedge} \mathrm{a}^{\circ}$ ".

Boroda: $\langle\operatorname{mor}$ acc sg $\rangle=$ borod $^{\wedge} \mathrm{u}$.

Boroda: $\langle\operatorname{mor}$ gen $\mathrm{sg}\rangle=\operatorname{borod}^{\wedge} i \circ "$.

Boroda: $\langle\operatorname{mor}$ dat $\mathrm{sg}\rangle=\operatorname{borod} \wedge \mathrm{e}^{\circ "}$.

Boroda: 〈mor inst sg $\rangle=$ borod ^ oj $\circ "$.

Boroda: $\langle\operatorname{mor} l o c s g\rangle=\operatorname{borod}^{\wedge} e^{\circ "}$.
Boroda: $\langle\operatorname{mor}$ nom pl $\rangle=\operatorname{borod}^{\wedge} i$.

Boroda: $\langle\operatorname{mor}$ acc pl $\rangle=\operatorname{borod} \wedge i$.

Boroda: $\langle$ mor gen pl $\rangle=$ borod ${ }^{\circ} "$.

Boroda: $\langle\operatorname{mor}$ dat $\mathrm{pl}\rangle=\operatorname{borod} \wedge \mathrm{a} \circ " \wedge \mathrm{m}$.

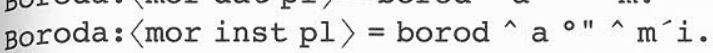

Boroda: $\langle\operatorname{mor} l o c p l\rangle=\operatorname{borod}^{\wedge} \mathrm{a}^{\circ " \wedge} \mathrm{x}$.

Boroda: $\langle$ syn gender $\rangle=$ fem .

Boroda: 〈syn animacy $\rangle=$ inanimate.

ćerta: $\langle$ gloss $\rangle=$ charateristic .

$\check{c}^{\prime}$ erta: $\langle\operatorname{mor}$ nom sg $\rangle=\bar{c}^{\prime}$ ert ${ }^{\wedge} \mathrm{a}^{\circ} "$.

$\check{C}^{\prime}$ erta: $\langle\operatorname{mor}$ acc sg $\rangle=\bar{c}^{\prime}$ ert ${ }^{\wedge} \mathrm{u} \circ "$.

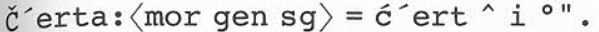

$\check{C}^{\prime}$ erta: $\langle$ mor dat $\mathrm{sg}\rangle=\mathrm{c}^{\prime}$ ert ${ }^{\wedge} \mathrm{e}^{\circ "}$.

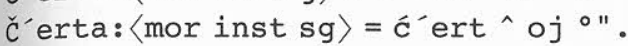

$\mathrm{C}^{\prime}$ erta: $\langle\operatorname{mor}$ loc sg $\rangle=\bar{c}^{\prime}$ ert ${ }^{\wedge} \mathrm{e}^{\circ "}$.

$\check{c}^{\prime}$ erta: $\langle$ mor nom pl $\rangle=\bar{c}^{\prime}$ ert ${ }^{\wedge} i \circ "$.

$\check{C}^{\prime}$ erta: $\langle\operatorname{mor}$ acc pl $\rangle=\bar{c}^{\prime}$ ert ${ }^{\wedge} i \circ "$.

$\check{c}^{\prime}$ erta: $\langle\operatorname{mor}$ gen pl $\rangle=\bar{c}^{\prime}$ ert ${ }^{\circ} "$

$\check{c}^{\prime}$ erta: $\langle$ mor dat $\mathrm{pl}\rangle=\bar{c}^{\prime}$ ert ${ }^{\wedge} \mathrm{a}^{\circ " \wedge} \mathrm{m}$.

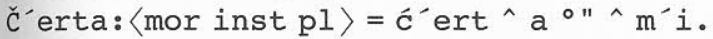

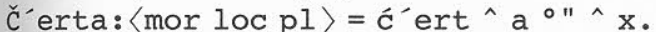

$\check{C}^{\prime}$ erta: $\langle$ syn gender $\rangle=$ fem .

ć' erta: $\langle$ syn animacy $\rangle=$ inanimate.

Dira: $\langle$ gloss $\rangle=$ hole.

Dira: $\langle$ mor nom sg $\rangle=\operatorname{dir} \wedge a^{\circ "}$.

Dira: $\langle\operatorname{mor}$ acc $\mathrm{sg}\rangle=\operatorname{dir}{ }^{\wedge} \mathrm{u} \circ "$.

Dira: $\langle$ mor gen $\mathrm{sg}\rangle=\operatorname{dir}{ }^{\wedge} i^{\circ}$.

Dira: $\langle$ mor dat $\mathrm{sg}\rangle=\operatorname{dir} \wedge \mathrm{e}^{0 "}$.

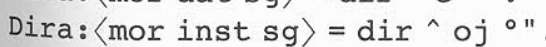

Dira: $\langle\operatorname{mor} \operatorname{loc} \mathrm{sg}\rangle=\operatorname{dir}{ }^{\wedge} \mathrm{e}^{\circ "}$.

Dira: $\langle$ mor nom pl $\rangle=\operatorname{dir} \wedge i$.

Dira: $\langle\operatorname{mor} \operatorname{acc} p l\rangle=\operatorname{dir} \wedge i$

Dira: $\langle$ mor gen $\mathrm{pl}\rangle=\operatorname{dir}$.

Dira: $\langle\operatorname{mor} \operatorname{dat} \mathrm{pl}\rangle=\operatorname{dir} \wedge \mathrm{a} \wedge \mathrm{m}$.

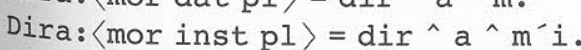

Dira: $\langle\operatorname{mor}$ loc pl $\rangle=\operatorname{dir}^{\wedge} \mathrm{a}^{\wedge} \mathrm{x}$.

Dira: $\langle$ syn gender $\rangle=$ fem .

Dira: $\langle$ syn animacy $\rangle=$ inanimate.

Dol' ${ }^{-a}:\langle$ gloss $\rangle=$ portion .

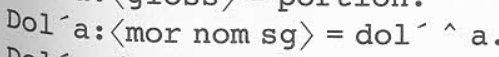

Dol' $\mathrm{a}:\langle\operatorname{mor}$ acc sg $\rangle=\operatorname{dol}^{-} \wedge \mathrm{u}$.

Dol' ${ }^{-} \mathrm{a}:\langle\operatorname{mor}$ gen $\mathrm{sg}\rangle=\mathrm{dol}^{-\wedge} i$.

Dol' ${ }^{-} \mathrm{a}:\langle\operatorname{mor}$ dat $\mathrm{sg}\rangle=\mathrm{dol}^{-}{ }^{\wedge} \mathrm{e}$.

Dol' $\mathrm{a}$ : $\langle$ mor inst sg $\rangle=\mathrm{dol}^{-}{ }^{\circ} \mathrm{oj}$. 
Dol' ${ }^{\prime} a:\langle\operatorname{mor}$ loc sg $\rangle=$ dol' $^{\prime} \wedge$ e. Dol' ${ }^{\prime} a:\langle\operatorname{mor}$ nom $p l\rangle=\operatorname{dol}^{\prime} \wedge i$.

Dol' ${ }^{\prime}$ : $\langle\operatorname{mor}$ acc pl $\rangle=\operatorname{dol}^{\prime} \wedge i$. Dol' ${ }^{\prime}$ : $\langle$ mor gen pl $\rangle=\operatorname{dol}^{\prime} \wedge^{\wedge} \mathrm{ej}^{\circ}$ ". Dol' $\mathrm{a}:\langle\operatorname{mor} \operatorname{dat} \mathrm{pl}\rangle=\mathrm{dol}^{\prime} \wedge \mathrm{a}^{\circ}{ }^{\prime \prime} \wedge \mathrm{m}$.

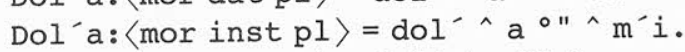
Dol' $a:\langle\operatorname{mor} l o c \mathrm{pl}\rangle=\operatorname{dol}^{\prime} \wedge \mathrm{a}^{\circ " \wedge} \mathrm{x}$. Dol' $a:\langle$ syn gender $\rangle=$ fem . Dol' ${ }^{\prime} a:\langle$ syn animacy $\rangle=$ inanimate.

Duša: $\langle$ gloss $\rangle=$ soul.

Duša: $\langle\operatorname{mor}$ nom sg $\rangle=$ duš ^ $a^{\circ "}$. Duša: $\langle\operatorname{mor}$ acc sg $\rangle=$ duš ^ $u$. Duša: $\langle$ mor gen $\mathrm{sg}\rangle=$ duš $\wedge i \circ "$. Duša: $\langle\operatorname{mor}$ dat $\mathrm{sg}\rangle=\operatorname{duš} \wedge \mathrm{e}^{\circ "}$. Duša: $\langle$ mor inst $s g\rangle=d u s ̌{ }^{\wedge} \circ j^{\circ "}$.

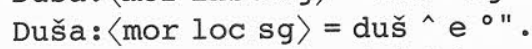
Duša: $\langle\operatorname{mor}$ nom pl $\rangle=$ duš ^ $i$.

Duša: $\langle\operatorname{mor}$ acc pl $\rangle=$ duš ^ $i$. Duša: $\langle$ mor gen pl $\rangle=$ duš . Duša: $\langle\operatorname{mor}$ dat $\mathrm{pl}\rangle=\operatorname{duš\wedge } \mathrm{a}^{\wedge} \mathrm{m}$. Duša: 〈mor inst pl $\rangle=$ duš ^ $\mathrm{a}^{\wedge} \mathrm{m}^{\prime} i$. Duša: $\langle\operatorname{mor}$ loc pl $\rangle=$ duš ^ $\mathrm{a} \wedge \mathrm{x}$. Duša: $\langle$ syn gender $\rangle=$ fem .

Duša: $\langle$ syn animacy $\rangle=$ inanimate.

Komnata: $\langle$ gloss $\rangle=$ room .

Komnata: $\langle$ mor nom sg $\rangle=$ komnat $^{\wedge} a$. Komnata: $\langle\operatorname{mor}$ acc $s g\rangle=$ komnat $^{\wedge} \mathrm{u}$. Komnata: $\langle\operatorname{mor}$ gen sg $\rangle=\operatorname{komnat}^{\wedge} i$. Komnata: $\langle\operatorname{mor} \operatorname{dat} \mathrm{sg}\rangle=\mathrm{komnat}^{\wedge} \mathrm{e}$. Komnata: $\langle$ mor inst $s g\rangle=$ komnat $^{\wedge}$ oj Komnata: $\langle\operatorname{mor}$ loc sg $\rangle=$ komnat $^{\wedge} \mathrm{e}$. Komnata: $\langle\operatorname{mor}$ nom pl $\rangle=$ komnat $^{\wedge} i$. Komnata: $\langle$ mor acc pl $\rangle=$ komnat $^{\wedge} i$. Komnata: $\langle$ mor gen pl $\rangle=$ komnat . Komnata: $\langle$ mor dat $\mathrm{pl}\rangle=$ komnat $^{\wedge} \mathrm{a} \wedge \mathrm{m}$. Komnata : $\langle$ mor inst pl $\rangle=$ komnat $^{\wedge} \mathrm{a}^{\wedge} \mathrm{m}^{\prime} i$. Komnata: $\langle\operatorname{mor}$ loc pl $\rangle=\operatorname{komnat}^{\wedge} \mathrm{a}^{\wedge} \mathrm{x}$. Komnata: $\langle$ syn gender $\rangle=$ fem .

Komnata: $\langle$ syn animacy $\rangle=$ inanimate.

Kon $^{\prime}:\langle$ gloss $\rangle=$ horse .

Kon $^{-}:\langle$mor nom sg $\rangle=$kon $^{-} \circ "$

Kon ${ }^{\prime}:\langle\operatorname{mor}$ acc sg $\rangle=\mathrm{kon}^{-} \wedge \mathrm{a}^{\circ "}$.

Kon $^{\prime}:\langle$ mor gen $\mathrm{sg}\rangle=\mathrm{kon}^{-\wedge} \mathrm{a}^{\circ} "$.

Kon ${ }^{\prime}:\langle\operatorname{mor} \operatorname{dat} \mathrm{sg}\rangle=\mathrm{kon}^{-} \wedge \mathrm{u}{ }^{\circ}$ ".
Kon' ${ }^{\prime}\langle$ mor inst sg $\rangle=$ kon $^{\prime} \wedge$ om $^{\circ} "$. Kon' ${ }^{\prime}:\langle\operatorname{mor}$ loc sg $\rangle=\mathrm{kon}^{-}{ }^{\wedge} \mathrm{e}^{\circ "}$. ROn' $:\langle$ mor nom pl $\rangle=$ kon $^{\prime} \wedge i$. Kon ${ }^{\prime}:\langle\operatorname{mor}$ acc pl $\rangle=k_{\text {kon }}{ }^{\prime} \wedge$ ej $\circ "$. Kon': 〈mor gen pl〉 = kon'^ ej ${ }^{\circ} "$. Kon' $:\langle$ mor dat $\mathrm{pl}\rangle=\mathrm{kon}^{-\wedge} \mathrm{a}^{\circ " \wedge} \mathrm{m}$.

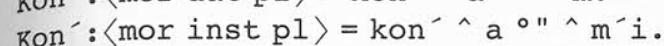

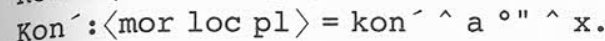
Kon ${ }^{\prime}:\langle$ syn gender $\rangle=\operatorname{masc}$.

Kon ${ }^{\prime}:\langle$ syn animacy $\rangle=$ animate.

Mesto: $\langle$ gloss $\rangle=$ place

Mesto: $\langle$ mor nom sg $\rangle=$ mest ${ }^{\wedge} 0$. Mesto: $\langle\operatorname{mor}$ acc $\mathrm{sg}\rangle=$ mest ${ }^{\wedge} 0$. Mesto: $\langle$ mor gen $\mathrm{sg}\rangle=$ mest $\wedge \mathrm{a}$. Mesto: $\langle$ mor dat $\mathrm{sg}\rangle=$ mest $^{\wedge} \mathrm{u}$. Mesto: $\langle$ mor inst $\mathrm{sg}\rangle=$ mest $^{\wedge}$ om . Mesto: $\langle\operatorname{mor} l o c s g\rangle=$ mest $^{\wedge} \mathrm{e}$. Mesto: $\langle\operatorname{mor}$ nom pl $\rangle=$ mest $^{\wedge} \mathrm{a}^{\circ}$ ". Mesto: $\langle\operatorname{mor}$ acc $\mathrm{pl}\rangle=$ mest ${ }^{\wedge} \mathrm{a}^{\circ}$ ". Mesto: $\langle$ mor gen pl $\rangle=$ mest ${ }^{\circ} "$. Mesto: $\langle\operatorname{mor}$ dat $\mathrm{pl}\rangle=$ mest ${ }^{\wedge} \mathrm{a}^{\circ " \wedge} \mathrm{m}$. Mesto: $\langle$ mor inst pl $\rangle=$ mest ${ }^{\wedge} a{ }^{\circ} \wedge \mathrm{m}^{\prime} i$. Mesto: $\langle\operatorname{mor}$ loc pl $\rangle=\operatorname{mest}{ }^{\wedge} \mathrm{a}{ }^{\circ} \wedge \wedge \mathrm{x}$. Mesto: $\langle$ syn gender $\rangle=$ neut . Mesto: 〈syn animacy $\rangle=$ inanimate.

Mozg: $\langle$ gloss $\rangle=$ brain.

Mozg: $\langle$ mor nom sg $\rangle=$ mozg . Mozg: $\langle\operatorname{mor}$ acc sg $\rangle=\operatorname{mozg}$. Mozg: $\langle\operatorname{mor}$ gen $\mathrm{sg}\rangle=\operatorname{mozg}^{\wedge} \mathrm{a}$.

Mozg: $\langle$ mor dat $\mathrm{sg}\rangle=\operatorname{mozg}^{\wedge} \mathrm{u}$.

Mozg: $\langle$ mor inst $\mathrm{sg}\rangle=\mathrm{mozg}^{\wedge} \mathrm{om}$. Mozg: $\langle\operatorname{mor}$ loc $\mathrm{sg}\rangle=\mathrm{mozg}^{\wedge} \mathrm{e}$.

Mozg: $\langle$ mor nom pl $\rangle=\mathrm{mozg}^{\wedge} i \circ "$. Mozg: $\langle\operatorname{mor}$ acc pl $\rangle=\operatorname{mozg}^{\wedge} i \circ "$. Mozg: $\langle$ mor gen pl $\rangle=\operatorname{mozg}{ }^{\wedge}$ ov $\circ "$. Mozg: $\langle$ mor dat pl $\rangle=\operatorname{mozg} \wedge \mathrm{a}^{\circ " \wedge}$.

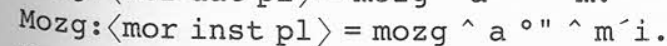
Mozg: $\langle\operatorname{mor} l o c \mathrm{pl}\rangle=\mathrm{mozg}^{\wedge} \mathrm{a}^{\circ " \wedge} \mathrm{x}$. Mozg: $\langle$ syn gender $\rangle=\operatorname{masc}$.

Mozg: $\langle$ syn animacy $\rangle=$ animate.

Plošč ${ }^{\prime}$ ad $^{\prime}:\langle$ gloss $\rangle=$ city_square.

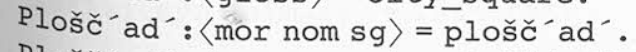
Plošč ${ }^{\prime}$ ad $^{\prime}:\langle\operatorname{mor}$ acc sg $\rangle=$ plošč ${ }^{\prime} \mathrm{ad}^{\prime}$.

Plošč ${ }^{\prime}$ ad $^{\prime}:\langle\operatorname{mor}$ gen $\mathrm{sg}\rangle=$ plošč $^{\prime} \mathrm{ad}^{\prime}{ }^{\prime} i$. 
Plošč ${ }^{\prime} \operatorname{ad}^{\prime}:\langle\operatorname{mor}$ dat $\mathrm{sg}\rangle=$ plošč $^{\prime} \operatorname{ad}^{\prime} \wedge i$.

Plošč ${ }^{\prime} \mathrm{ad}^{\prime}:\langle\operatorname{mor}$ inst sg $\rangle=$ plošč $^{\prime} \mathrm{ad}^{\prime} \wedge$ ju.

Plošč ${ }^{\prime}$ ad $^{\prime}:\langle\operatorname{mor}$ loc sg $\rangle=$ plošč $^{\prime} \mathrm{ad}^{\prime} \wedge i$.

Plošč ${ }^{\prime} \mathrm{ad}^{\prime}$ : $\langle\operatorname{mor}$ nom pl $\rangle=$ plošč $^{\prime} \mathrm{ad}^{\prime} \wedge i$.

Plošč ${ }^{\prime} \mathrm{ad}^{\prime}:\langle\operatorname{mor}$ acc pl $\rangle=$ plošč $^{\prime} \mathrm{ad}^{\prime} \wedge i$.

Plošč ${ }^{\prime}$ ad $^{\prime}:\langle\operatorname{mor}$ gen pl $\rangle=$ plošč $^{\prime}$ ad $^{\prime} \wedge$ ej $\circ "$.

Plošč ${ }^{\prime} \mathrm{ad}^{\prime}:\langle\operatorname{mor}$ dat $\mathrm{pl}\rangle=\mathrm{plošč}{ }^{\prime} \mathrm{ad}^{\prime} \wedge \mathrm{a}^{\circ} " \wedge \mathrm{m}$.

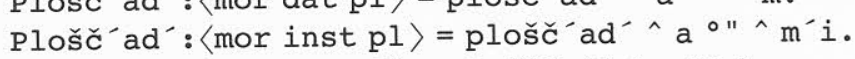

Plošč ${ }^{\prime} a^{\prime}:\langle\operatorname{mor}$ loc pl $\rangle=$ plošč ${ }^{\prime} a^{\prime} \wedge a^{\circ " \wedge} \mathrm{x}$.

Plošč ${ }^{\prime}$ ad $^{\prime}:\langle$ syn gender $\rangle=$ fem .

Plošč ${ }^{\prime}$ ad $^{\prime}$ : $\langle$ syn animacy $\rangle=$ inanimate.

Skovoroda: $\langle$ gloss $\rangle$ = frying_pan.

Skovoroda: $\langle\operatorname{mor}$ nom sg $\rangle=\operatorname{skovorod}^{\wedge} \mathrm{a}^{\circ "}$.

Skovoroda: $\langle\operatorname{mor}$ acc $\mathrm{sg}\rangle=\operatorname{skovorod}^{\wedge} \mathrm{u} \circ "$.

Skovoroda: $\langle\operatorname{mor}$ gen $\mathrm{sg}\rangle=\operatorname{skovorod}^{\wedge} i \circ "$.

Skovoroda: $\langle\operatorname{mor}$ dat $\mathrm{sg}\rangle=\mathrm{skovorod}^{\wedge} \mathrm{e}^{\circ "}$.

Skovoroda: $\langle\operatorname{mor}$ inst sg $\rangle=$ skovorod ^ oj $\circ "$.

Skovoroda: $\langle\operatorname{mor}$ loc sg $\rangle=$ skovorod $^{\wedge} \mathrm{e}^{\circ "}$.

Skovoroda: $\langle\operatorname{mor}$ nom pl $\rangle=\operatorname{skovorod}^{\wedge} i$.

Skovoroda: $\langle\operatorname{mor}$ acc pl $\rangle=\operatorname{skovorod}^{\wedge} i$.

Skovoroda: $\langle$ mor gen pl〉 $=$ skovorod $\circ "$.

Skovoroda: $\langle\operatorname{mor}$ dat $\mathrm{pl}\rangle=\operatorname{skovorod}^{\wedge} \mathrm{a}^{\circ \| \wedge} \mathrm{m}$.

Skovoroda: $\langle\operatorname{mor}$ inst $\mathrm{pl}\rangle=\operatorname{skovorod}^{\wedge} \mathrm{a}^{\circ} " \wedge \mathrm{m}^{\prime} \mathrm{i}$.

Skovoroda: $\langle\operatorname{mor} l o c \mathrm{pl}\rangle=\operatorname{skovorod}^{\wedge} \mathrm{a}^{\circ " \wedge} \mathrm{x}$.

Skovoroda: $\langle$ syn gender $\rangle=$ fem .

Skovoroda: $\langle$ syn animacy $\rangle=$ inanimate.

\section{$\mathrm{S}^{\prime}$ olo: $\langle$ gloss $\rangle=$ village.}

$\mathrm{S}^{\prime}$ olo: $\langle$ mor nom sg $\rangle=\mathrm{s}^{\prime} \mathrm{ol} \wedge \mathrm{O}^{\circ}$.

$\mathrm{s}^{\prime}$ olo: $\langle\operatorname{mor}$ acc $\mathrm{sg}\rangle=\mathrm{s}^{\prime} \mathrm{ol} \wedge \mathrm{O}^{\circ}$ ".

$\mathrm{S}^{\prime}$ olo: $\langle\operatorname{mor}$ gen $\mathrm{sg}\rangle=\mathrm{s}^{\prime} \mathrm{ol} \wedge \mathrm{a}^{\circ}$ ".

$\mathrm{S}^{\prime} \mathrm{olo}:\langle\operatorname{mor}$ dat $\mathrm{sg}\rangle=\mathrm{s}^{\prime} \mathrm{ol} \wedge \mathrm{u}{ }^{\circ}$ ".

$\mathrm{S}^{\prime} \mathrm{olo}$ : $\langle$ mor inst $\mathrm{sg}\rangle=\mathrm{s}^{\prime} \mathrm{ol}{ }^{\wedge} \mathrm{om}{ }^{\circ}$ " .

$\mathrm{S}^{\prime}$ olo: $\langle\operatorname{mor}$ loc $\mathrm{sg}\rangle=\mathrm{s}^{\prime} \mathrm{ol} \wedge \mathrm{e}^{\circ}$ ".

$\mathrm{s}^{\prime}$ olo: $\left\langle\right.$ mor nom pl $>\mathrm{s}^{\prime} \mathrm{ol} \wedge \mathrm{a}$.

$\mathrm{S}^{\prime} \mathrm{olo}:\langle\operatorname{mor}$ acc pl $\rangle=\mathrm{s}^{\prime} \mathrm{ol} \wedge \mathrm{a}$.

$\mathrm{s}^{\prime} \mathrm{olo}:\langle\operatorname{mor}$ gen $\mathrm{pl}\rangle=\mathrm{s}^{\prime} \mathrm{ol}$.

$\mathrm{S}^{\prime}$ olo: $\langle$ mor dat $\mathrm{pl}\rangle=\mathrm{s}^{\prime} \mathrm{ol} \wedge \mathrm{a} \wedge \mathrm{m}$.

$\mathrm{S}^{\prime} \mathrm{olo}$ : $\left\langle\right.$ mor inst pl> $=\mathrm{s}^{\prime} \mathrm{ol}{ }^{\wedge} \mathrm{a}^{\wedge} \mathrm{m}^{\prime} \mathrm{i}$.

$\mathrm{S}^{\prime}$ olo: $\langle\operatorname{mor}$ loc $\mathrm{pl}\rangle=\mathrm{s}^{\prime} \mathrm{ol} \wedge \mathrm{a} \wedge \mathrm{x}$.

$\mathrm{S}^{\prime}$ olo: $\langle$ syn gender $\rangle=$ neut .

$\mathrm{S}^{\prime} \mathrm{olo}$ : $\langle$ syn animacy $\rangle=$ inanimate.

Stol: $\langle$ gloss $\rangle=$ table.

Stol: $\langle$ mor nom sg $\rangle=$ stol ${ }^{\circ}$.

Stol: $\langle\operatorname{mor}$ acc sg $\rangle=$ stol ${ }^{\circ}$ ". stol: $\langle$ mor gen $\mathrm{sg}\rangle=\mathrm{stol}^{\wedge} \mathrm{a}$ " . stol: $\langle\operatorname{mor}$ dat $\mathrm{sg}\rangle=\mathrm{stol}^{\wedge} \mathrm{u}{ }^{\circ}$ ".

Stol: $\langle$ mor inst sg $\rangle=$ stol $^{\wedge} \mathrm{om}^{\circ} "$. Stol: $\langle\operatorname{mor}$ loc sg $\rangle=$ stol $^{\wedge} \mathrm{e}^{\circ " \text {. }}$ Stol: $\langle$ mor nom pl $\rangle=$ stol $i \circ "$. stol: $\langle\operatorname{mor}$ acc pl $\rangle=$ stol ${ }^{\circ} \circ "$.

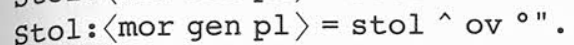
Stol: $\langle$ mor dat $\mathrm{pl}\rangle=\mathrm{stol}^{\wedge} \mathrm{a}^{\circ " \wedge} \mathrm{m}$.

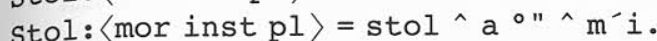
Stol: $\langle\operatorname{mor}$ loc pl $\rangle=$ stol $^{\wedge} \mathrm{a}^{\circ " \wedge} \mathrm{x}$. Stol: $\langle$ syn gender $\rangle=\operatorname{masc}$.

stol: $\langle$ syn animacy $\rangle=$ inanimate.

Vešč estvo: $\langle$ gloss $\rangle=$ substance.

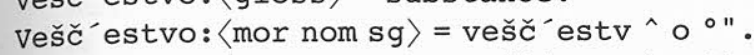
Vešč estvo: $\langle\operatorname{mor}$ acc $s g\rangle=$ vešč ${ }^{\prime}$ estv ${ }^{\wedge} 0^{\circ} "$.

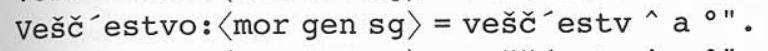

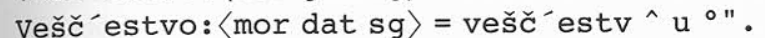

Vešč ${ }^{\prime}$ estvo: $\langle$ mor inst $\mathrm{sg}\rangle=$ vešč $^{\prime}$ estv ${ }^{\wedge} \mathrm{om}^{\circ} "$.

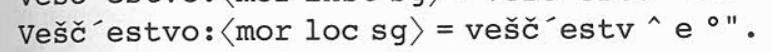

Vešč ${ }^{\prime}$ estvo: $\langle\operatorname{mor}$ nom $\mathrm{pl}\rangle=$ vešč $^{\prime}$ estv ${ }^{\wedge} \mathrm{a}^{\circ} "$.

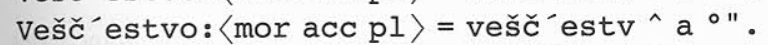

Vešč estvo: 〈mor gen $\mathrm{pl}\rangle=$ vešč $^{\prime}$ estv ${ }^{\circ} "$.

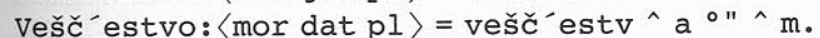

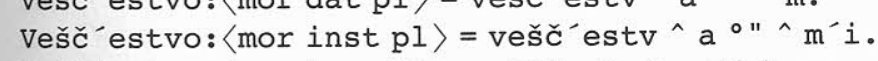

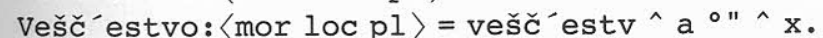

Vešč estvo: $\langle$ syn gender $\rangle=$ neut .

Vešč estvo: $\langle$ syn animacy $\rangle=$ inanimate.

Zakaz: $\langle$ gloss $\rangle=$ order .

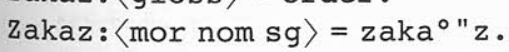

Zakaz: $\langle$ mor acc sg $\rangle=z^{2} a^{\circ} " z$.

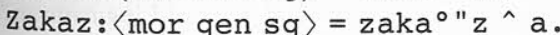

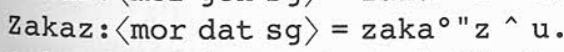

Zakaz: $\langle$ mor inst $\mathrm{sg}\rangle=\mathrm{zaka}^{\circ} " \mathrm{z}{ }^{\wedge} \mathrm{om}$

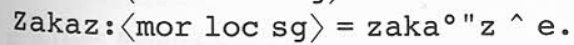

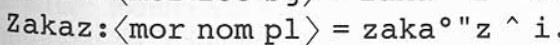

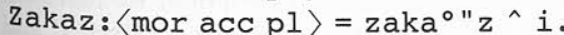

Zakaz: $\langle$ mor gen pl $\rangle=$ zaka $^{\circ} " \mathrm{z} \wedge$ ov .

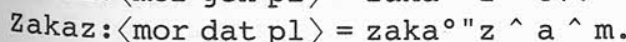

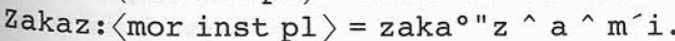

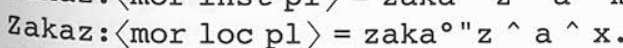

Zakaz: $\langle$ syn gender $\rangle=\operatorname{masc}$

Zakaz: 〈syn animacy $\rangle=$ inanimate.

Zub: $\langle$ gloss $\rangle=$ tooth .

$\mathrm{Zub}:\langle\operatorname{mor}$ nom sg $\rangle=\mathrm{zub}$. 
$\mathrm{Zub}:\langle\operatorname{mor}$ acc $\mathrm{sg}\rangle=\mathrm{zub}$.

$\mathrm{Zub}:\langle\operatorname{mor}$ gen $\mathrm{sg}\rangle=\mathrm{zub} \wedge \mathrm{a}$.

$\mathrm{Zub}:\langle\operatorname{mor}$ dat $\mathrm{sg}\rangle=\mathrm{zub}^{\wedge} \mathrm{u}$.

$\mathrm{zub}:\langle$ mor inst $\mathrm{sg}\rangle=\mathrm{zub}^{\wedge} \mathrm{om}$.

$\mathrm{Zub}:\langle\operatorname{mor} \mathrm{loc} \mathrm{sg}\rangle=\mathrm{zub} \wedge \mathrm{e}$.

$\mathrm{zub}:\langle\operatorname{mor}$ nom pl $\rangle=\mathrm{zub}^{\wedge} i$.

$\mathrm{Zub}:\langle\operatorname{mor}$ acc pl $\rangle=\mathrm{zub}^{\wedge} i$.

Zub: $\langle$ mor gen pl $\rangle=z u b^{\wedge}$ ov ${ }^{\circ}$.

$\mathrm{Zub}:\langle\operatorname{mor}$ dat $\mathrm{pl}\rangle=\mathrm{zub} \wedge \mathrm{a} \circ " \wedge \mathrm{m}$.

Zub: $\langle$ mor inst pl $\rangle=\mathrm{zub}^{\wedge} \mathrm{a}^{\circ " \wedge} \mathrm{m}^{\prime} i$.

$\mathrm{Zub}:\langle\operatorname{mor}$ loc pl $\rangle=\mathrm{zub}^{\wedge} \mathrm{a}^{\circ \| \wedge} \mathrm{x}$.

$\mathrm{Zub}:\langle$ syn gender $\rangle=\operatorname{masc}$.

$\mathrm{Zub}:\langle$ syn animacy $\rangle=$ inanimate.

\section{Notes}

* Dunstan Brown is the main author of this paper. The authors, with the exception of Alan Timberlake (University of California, Berkeley), are associated with the University of Surrey.

Earlier versions of parts of this paper were presented at the Third Manchester University Postgraduate Linguistics Conference, March 12, 1994, and the Linguistic Association of Great Britain Spring Meeting at Salford University, April 5-7, 1994. We would like to acknowledge the helpful comments and questions of John Local, Andrew Spencer, and Susan Steele at the LAGB conference. Thanks are due to Lynne Cahill and Gerald Gazdar for help and advice, and also to Tore Nesset for further suggestions for improvement and pointers to additional reference sources. Finally, we would like to thank an anonymous referee for critical comments and suggestions for improvement. All errors are ours. The research presented here was supported by the Economic and Social Science Research Council under grant number R000233633, and by the Leverhulme Trust under grant number F.242M. We gratefully acknowledge their support. Correspondence address: Dunstan Brown, Department of Linguistic and International Studies, University of Surrey, GB-Guildford GU2 5XH, UK.

1. This is a slight simplification. We also recognize a fifth group of indeclinable nouns, which we shall not discuss further here.

2. Stress is marked by an acute ' on the relevant vowel. The acute symbol ' after a consonant indicates palatalization ("softening"). In our transcription, we represen unstressed vowels in the underlying form they would have if they were stressed and assume that regular phonological rules will account for the details of vowel reduction. For discussion of the transcription used see Corbett and Fraser (1993: 114).

3. For a detailed discussion of the question of how accentual paradigms (patterns) are defined and established see Feldstein (1993).

4. We do not discuss certain wildly idiosyncratic alternations in the stem, such as that between the nominative singular per'ó 'front' and the genitive singular pér'od-a. The stress pattern of the pluralia tantum noun l'úd'-i 'people' is also highly idiosyncratic, with ending-stressed genitive $l^{\prime} u d-e ́ j$ and instrumental $l^{\prime} u d m^{\prime} i$, but stem-stressed dative and locative. Nouns such as dén' $g-i$ 'money', which is also pluralia tantum, have an odd genitive plural déneg, because we would expect the last syllable of the stem to be stressed, given that the other oblique plural endings are stressed. Such minor atternations, exhibited by a handful of lexemes, do not pose any problems of principle for the analysis proposed here and are not discussed further for the sake of clarity of exposition. Readers should also bear in mind the status of the so-called second locative in stressed $-\dot{u}$ for declension I. This ending is a true locative, which occurs together with the normal locative ending $-e$ and is always stressed. We would therefore have stress always associated with this ending in its representation. In contrast to this, the instrumental singular of class III nouns can never be stressed. We may note that our treatment of these endings follows the distinction that Vincent (1993: 24) draws between "paradigmatic" and "morphemic" stress in his discussion of Roca (1992). None of these facts is at odds with the line of argumentation that we follow.

5. In most instances the initial syllable is the predesinential syllable, because the majority of nouns of this pattern are monosyllabic. However, for pattern D nouns that have a stem consisting of more than one syllable, stem stress is on the last syllable of the stem. So we have examples such as kislot-á 'acid' and kislót-i 'acids', kolbas-á 'sausage' and kolbás-i 'sausages'. As pointed out by Stankiewicz (1993: 195) nouns of this type "are mostly derivatives with the suffixes -ot-(á) and -in-(á)"; for example, glub'in-á 'depth' and krasot-á 'beauty'. It should be noted that these nouns often denote abstract concepts, and that of the 19 declension II examples listed in Stankiewicz (1993: 195-196) only three ( past'il-á 'fruit tart', strekoz-á 'dragon-fly' and staršin-á 'foreman') do not easily allow for a singular-plural distinction on the basis of noncount opposed to count. Searching the electronic version of Zaliznjak (1977) (see note 6) also yields about 65 examples of polysyllabic class D nouns (out of 327 class D in total). Of these the vast majority belong to declension II. A number of other examples are excluded from this count, since they are marked as having a "hypothetical" plural, mainly because they are abstract nouns. It follows that these latter must be noncountable, and that their pluralization would make them countable. We treat the small handful of class IV nouns that have polysyllabic stems and stress pattern D as lexically exceptional. We assume that there is a lexicosemantic generalization that the mild allomorphy in stress placement on the stem between singular (no stress) and plural (on final syllable of stem) can be accounted for by assuming that the different placement of stress on the plural stem is generally the realization of a lexical difference between noncount (the singular) and count (the plural). This distinction is not inflectional and it is not our purpose here to consider it any further. Furthermore, it should be noted that all nouns following pattern $\mathrm{Di}$, a subpattern of $\mathrm{D}$, are monosyllabic, and therefore the distinction between predesinential and initial syllable is eliminated.

6. For similar information, see Zaliznjak (1967: 172-173) and Halle (1970: 174). This table has been compiled on the basis of data from Ilola and Mustajoki (1989) and the electronic version of Zaliznjak (1977), available from the Department of Slavonic Languages, University of Helsinki.

7. By convention, we set all nodes in full capitals, except lexical entry nodes, which have initial capitals; all other symbols are set in lower-case.

8. Contrary to appearances, DATR is NOT an acronym (Gerald Gazdar, personal communication). On the origins of DATR, Evans and Gazdar (1995: 3) note that "The syntax of DATR, like its name and its minimalist philosophy, owes more than a little to that of the unification grammar language PATR (Shieber 1986). With hindsight this may have been a bad design decision since similarity of syntax tends to imply a similarity of semantics. [But] ... there is an important difference." 
9. These terms are used to allow for the fact that the automatic phonology can supply a default stress. In effect, the DATR representation of the node STRESS in the hierarchy in Figure 4 is the following:

STRESS :

\langle\rangle$==$

$$
\langle\mathrm{pl}\rangle==\text { "〈mor stress sg }\rangle " .
$$

10. In a DATR representation of this hierarchy, quoted nodes are also used to specify that a value will be inherited from the node that is quoted, rather than a global evaluation specified at that node. For instance, in a representation of the node STRESS_D, the node STRESS is quoted:

\section{STRESS :}

\langle\rangle$==$ "STRESS"

$\langle\mathrm{sg}\rangle==$ STRESS_B.

This means that the plural is obtained, not by evaluating the value for $\langle\mathrm{sg}\rangle$ at STRESS_D, but by evaluating it at the node STRESS. This means that we can capture the fact that generally the plural follows the singular and at the same time allow node STRESS D to inherit the default value for plural.

11. Short-form adjectives are excluded from this, because they do not have the typical attributive function of adjectives. Possessive adjectives are also left out of consideration here.

12. There is also an independent motivation for using indices. This is to account for those declension I nouns that also have a different nominative plural in -á. As is well known among Russianists, these nouns will have stress on all desinences of the plural. This generalization would include pattern B, but we find that it applies to pattern C (index 3). In other words, we make the generalization that declension I nouns of index 3 have a nominative plural desinence in -á. If we take the first 1500 most frequent nouns from Zasorina (1977), this generalization is adhered to by $70 \%$ of class I nouns that are index 3. The generalization is that these nouns have $-a$, because they are index 3 , not just because they are ending-stressed throughout the plural (although this goes with being index 3 for class I). Among these 1500 nouns there are only two class I of index 2 (pattern B) that have the nominative plural in -á. Furthermore these two nouns (obšlág 'sleeve' and rukáv 'cuff') are semantically duals, a group that is also associated with this desinence.

13. Connections between nodes in the stress hierarchy and declension nodes where there are less than 20 representative lexemes for that given class and declension are not given for the sake of perspicuity. The index 3 between N_IV and N II indicates that the node N_II inherits via N_IV its third ranked stress pattern.

14. The order of attributes in the stress hierarchy is highly significant, but we make no theoretical claims for the difference in attribute ordering between the declension hierarchy and the stress hierarchy.

15. Although noninitial stress for nonderived nouns of this pattern would be marked as part of the value of the $\langle$ infl_root all $\rangle$ path.

16. The ${ }^{\circ}$ operator is used to indicate overlap, following Gibbon (1991: 5). For our purposes it indicates that stress is associated with the nearest stress-bearing unit to its left. By defining the operator in this way we allow for word forms such as boród 'beard' (genitive plural), represented as borod ${ }^{\circ}$. This is in line with Zalinznjak's (1967: 152) concept of "uslovnoe udarenie." The idea behind this is that stress would fall on an ending if there were one but is forced onto the last syllable of the stem, as there is no ending. The same is also the case for the class I nominative singular stol 'table', which we represent as stol ${ }^{\circ}$. Mustajoki $(1980 \mathrm{a}, 1981)$ argues that, while this approach is acceptable for the genitive plural, it cannot be extended to the nominative singular. His arguments can be summarized as follows: stress mobility is already present for the arguments can be summarized as follows: stress mobility is already present for the
nominative (in the plural); it is wrong to determine the nominative singular on the basis of oblique cases, as it is prior to them, as citation form and by virtue of its frequent use in speech; as there are differences in stress pattern across gender/declension, it is not valid to assume a pattern B applies to class I, just because it may apply to classes II or IV; words with mobile stress typically have concrete meaning and are used in the plural, and this is overwhelmingly true of those nouns for which Mustajoki rejects "uslovnoe udarenie" in the nominative singular.

Although we may attribute some validity to the view of nominative singular as having special status, it can easily be seen from our representation that the nominative singular stress is not based on the oblique, but on the value for singular in general. Our formalization requires us to be explicit in saying that the number distinction is of greater importance than the case distinction, a declaration borne out by the fact that all the logical possibilities for difference in number are realized. Furthermore, it is generally the case that such nouns are stressed on the final syllable, not the default, initial, syllable. Hence mužík 'bloke' (nom sg), mužik-á (gen sg), mužik-í (nom pl). If we assumed that there were some connection between the nominative plural and nominative singular alternation, patterns such as mužik, mužik-á, *mužík-i (where the rest of the plural is stressed on the ending) would be expected.

With associations where a consonant group (syllable coda) intervenes between the stress and its bearer it is required that the final element of the stem be divided from the rest. This can be achieved straightforwardly with maximal lexical encoding of phonological information in a nonredundant fashion, as exemplified by Gibbon's (1992) use of DATR for ILEX lexica.

17. It might be considered possible to correlate the indices with frequency. Zipf (1935: 147) noted the relationship between less common accent type and the frequency of occurrence of particular items, and this has not gone unnoticed for Russian (Cubberley 1987, for instance). Mustajoki (1982b: 127) also gives information related to data in Josselson (1951). Here it can be seen that in the first thousand most frequent words the prominence of the default patterns decreases relative to those of the minor patterns. However, sufficient information on this subject from corpora is not available.

18. This is not an analysis that makes diachronic claims. When we talk of possible changes we assume that the configuration of the whole network remains the same, other than that a lexical item could change its index within the limits allowed by its membership of a particular declension. We predict that a noun must first change declension class before it can develop a stress pattern that would otherwise not be allowed by its own declension. In principle any change of index within the possibilities of the declension is permitted. A class II noun for example could change indices from 5 to 6 to 4 , for example, as well as 5 to 4 to 3 . The former would allow for change from pattern Bii to Di to D, the latter from Bii to Bi to D. Both of these changes are attested. We rule out of consideration more radical qualitative differences brought about by migration of groups of nouns that is so qualitatively significant that it causes a diachronic change in the configuration of the network. This can be seen as analogous to historical migrations and eliminations of declensions. Of course, we must also bear in mind that the stress hierarchy itself constrains possible patterns, such that a class II noun, for example, could not have ending stress in all but the accusative singular. 


\section{References}

Bleiching, Doris (1992). Prosodisches Wissen im Lexikon. In KONVENS 92: Konferenz "Verarbeitung natürlicher Sprache," Günther Görz (ed.), 59-68. Berlin: Springer.

Brown, Dunstan; and Hippisley, Andrew (1994). Conflict in Russian genitive plural assignment: a solution represented in DATR. Journal of Slavic Linguistics 2(1), 48-76.

Carstairs, Andrew (1988). Nonconcatenative inflection and paradigm economy. In Theoretical Morphology: Approaches in Modern Linguistics, Michael Hammond and Michael Noonan (eds.), 71-79. London and San Diego: Academic Press.

Comrie, Bernard (1976). Irregular stress in Polish and Macedonian. International Review of Slavic Linguistics 1, 227-240.

-; and Stone, Gerald (1978). The Russian Language since the Revolution. Oxford: Oxford University Press.

Corbett, Greville G. (1982). Gender in Russian: an account of gender specification and its relationship to declension. Russian Linguistics 6, 197-232.

- (1989). The study of Russian stress patterns with advanced students. In Words and Images: Essays in Honour of Professor (Emeritus) Dennis Ward, M. Falchikov, C. Pike, and R. Russell (eds.), 53-65. Nottingham: Astra.

-; and Fraser, Norman M. (1993). Network morphology: a DATR account of Russian nominal inflection. Journal of Linguistics 29(1), 113-142.

Cubberley, Paul (1987). Stress patterns in high-frequency Russian nouns and verbs. Russian Language Journal 41, 31-44.

Daelemans, Walter; De Smedt, Koenraad; and Gazdar, Gerald (1992). Inheritance in natural language processing. Computational Linguistics 18(2), 205-218.

Evans, Roger; and Gazdar, Gerald (1989a). Inference in DATR. In Proceedings of the Fourth Conference of the European Chapter of the Association for Computational Linguistics, 10-12 April 1989, 66-71. Manchester: University of Manchester Institute of Science and Technology.

-; and Gazdar, Gerald (1989b). The semantics of DATR. In Proceedings of the Seventh Conference of the Society for the Study of Artificial Intelligence and Simulation of Behaviour, A. G. Cohn (ed.), 79-87. London: Pitman.

-; and Gazdar, Gerald (1995). DATR: A Language for Lexical Knowledge Representation. Cognitive Science Research Paper CSRP 382. Brighton: University of Sussex.

Fahlman, Scott E. (1979). Representing and using real-world knowledge. In Artificial Intelligence: An MIT Perspective, Patrick H. Winston and R. H. Brown (eds.), vol. 1, 451-470. Cambridge, MA: MIT Press.

Fedjanina, Nina A. (1976). Udarenie v sovremennom russkom jazyke. Moscow: Russkij jazyk.

Feldstein, Ronald F. (1984). Stress restrictions in Russian nominal derivation. Slavic and East European Journal 28(4), 502-510.

- (1993). The nature and use of the accentual paradigm as applied to Russian. Journal of Slavic Linguistics 1(1), 44-60.

Franks, Steven L. (1987). Regular and irregular stress in Macedonian. International Journal of Slavic Linguistics and Poetics 35/36, 93-142.

Fraser, Norman M.; and Corbett, Greville G. (1995). Gender, animacy, and declensional class assignment: a unified account for Russian. In Yearbook of Morphology 1994, Gert Booij and Jaap van Marle (eds.), 123-150. Dordrecht: Kluwer.

-; and Hudson, Richard (1992). Inheritance in word grammar. Computational Linguistics $18(2), 133-158$

Gazdar, Gerald (i.p.). Ceteris paribus. In Aspects of Computational Linguistics, J. A. W. Kamp and C. Rohrer (eds.). Berlin: Springer.
Gibbon, Dafydd (1991). Lexical signs and lexicon structure: phonology and prosody in the ASL-lexicon. ASL-MEMO-20-91/UBI. University of Bielefeld.

(1992). ILEX: a linguistic approach to computational lexica. In Aufsätze zur algorithmischen und quantitativen Analyse der Sprache, Ursula Klenk (ed.), 32-53. Stuttgart: Franz Steiner.

Halle, Morris (1970). A note on the accentual patterns of the Russian nominal declension. In Studies in General and Oriental Linguistics, R. Jakobson and S. Kawamoto (eds.), 167-174. Tokyo: TEC

(1973). The accentuation of Russian words. Language 49(2), 312-348

- (1975). On Russian accentuation. Slavic and East European Journal 19(1), 104-111.

- (1990). An approach to morphology. Paper presented at NELS, BLSA Twentieth Annual Meeting, University of Massachusetts, Amherst.

. Harris, James W; and Vergnaud, Jean-Roger (1991). A reexamination of the stress erasure convention and Spanish stress. Linguistic Inquiry 22(1), 141-159.

; and Vergnaud, Jean-Roger (1987). An Essay on Stress. Cambridge, MA: MIT Press.

Hudson, Richard (1990). English Word Grammar. Oxford: Blackwell.

Ilola, Eeva; and Mustajoki, Arto (1989). Report on Russian Morphology as It Appears in Zaliznyak's Grammatical Dictionary. Slavica Helsingiensia 7. Helsinki: Department of Slavonic Languages, University of Helsinki.

Josselson, H. H. (1951). Stress patterns of the noun declension in Standard Russian. Unpublished Ph.D. dissertation, University of Michigan.

Kiparsky, Paul; and Halle, Morris (1978). Towards a reconstruction of the Indo-European accent. Southern California Occasional Papers in Linguistics 4, 209-238.

Liberman, Mark (1975). The intonational system of English. Unpublished Ph.D. dissertation, MIT.

-; and Prince, Alan (1977). On stress and linguistic rhythm. Linguistic Inquiry 8(2), 249-336.

Mustajoki, Arto (1980a). K voprosu o ponjatii "uslovnoe udarenie” i tipax udarenija suščestvitel'nyx v russkom jazyke. Voprosy jazykoznanija (2), 80-86.

-(1980b). Tipy udarenija imen suščestvitel'nyx $v$ sovremennom russkom literaturnom jazyke $i$ ix minimizacija $v$ učebnyx celjax. (Neuvostoliittoinstituutin vuosikirja, 26.) Helsinki: Institute for Cultural Contacts between Finland and the USSR.

- (1981). O russkom udarenii: stól + Ø ili stol + Ǿ? Russian Linguistics 6, 103-119.

Nesset Tore (1993). Semiotičeskie aspekty udarenija russkix suščestvitel'nyx. In Norvežskie doklady na XI-om s"ezde slavistov, Bratislava, September, 1993, Jan Ivar Bjørnflaten, Tore Nesset, and Erik Egeberg (eds.), 23-33. Oslo: University of Oslo.

Redkin, V. A. (1971). Akcentologija sovremennogo russkogo literaturnogo jazyka: posobie dlja učitelej. Moscow: Prosveščenie.

Roca, Iggy (1992). On the sources of word prosody. Phonology 9(2), 267-287.

Shieber, Stuart M. (1986). An Introduction to Unification Grammar. Stanford: CSLI and University of Chicago Press.

Stankiewicz, Edward (1993). The Accentual Patterns of the Slavic Languages. Stanford: Stanford University Press.

Touretzky, David S. (1986). The Mathematics of Inheritance Systems. London: Pitman.

Vincent, Nigel (1993). On paradigmatic stress. Paper presented at the Workshop on Cognitive Phonology, University of Manchester, Manchester, May 21.

Zaliznjak, A. A. (1967). Russkoe imennoe slovoizmenenie. Moscow: Nauka.

- (1977). Grammatičeskij slovar' russkogo jazyka. Moscow: Russkij jazyk.

- (1985). Ot praslavjanskoj akcentuacii k russkoj. Moscow: Nauka.

Zasorina, L. N. (1977). Častotnyj slovar' russkogo jazyka. Moscow: Russkij jazyk.

Zipf, George Kingsley (1935). The Psycho-Biology of Language: An Introduction to Dynamic Philology. Cambridge, MA: MIT Press. 